MARDONES, Daniela: "Representación mediática y cobertura de los medios de las mujeres

víctimas de violencia intrafamiliar en Chile: El caso de Nabila Rifo".

Polít. Crim. Vol. 15, No 29 (Julio 2020), Art. 12, pp. 331-361

[http://politcrim.com/wp-content/uploads/2020/07/Vol15N29A12.pdf]

\title{
Representación mediática y cobertura de los medios de las mujeres víctimas de violencia intrafamiliar en Chile: El caso de Nabila Rifo*
}

\section{Media Representation and News Coverage of Female Victims of Domestic Violence in Chile: The Nabila Rifo Case}

\author{
Daniela Mardones Bravo \\ PhD Candidate, University of Edinburgh. \\ daniela.Mardones-Bravo@ed.ac.uk
}

\section{Resumen}

Nabila Rifo fue atacada en la calle en el año 2016, fue golpeada en el cráneo y le removieron sus globos oculares. Se determinó que el autor de esos hechos fue su pareja y padre de dos de sus hijos. Este acontecimiento fue expuesto por los medios de comunicación por más de dos años, incluyendo la transmisión de su juicio. Este artículo desarrolla un estudio del caso desde la perspectiva de las teorías criminológicas relacionadas con los medios de comunicación y la victimología con el fin de explicar cómo y por qué se fue transformando la imagen de Nabila como víctima y cómo fue mutando el valor noticioso de la misma con el fin de mantener su vigencia. Para ello, el análisis se divide en tres etapas clave: 1. Investigación, donde se asocia a los conceptos de víctima ideal, culpar a la víctima y la personalización. 2. Juicio, relacionado con el juicio mediático y el valor noticioso. 3. Post-juicio desarrollando las teorías sobre escándalo y fracaso institucional.

Palabras clave: criminología, victimología, medios de comunicación, valor noticioso.

\begin{abstract}
Nabila Rifo was attacked on the street in 2016, she was beaten in the skull and her eyeballs were removed. It was determined that the author of these acts was her partner and the father of two of her children. Her case was exposed by the media for more than two years, including the transmission of the trial. This article develops a case study from the perspective of the criminological theories related to the media and victimology in order to explain how and why the image of Nabila was transformed as a victim and how the news value was changing in order to maintain its newsworthiness. To do so, the case was divided into three key stages: 1 . Research, where it is associated with the concepts of the ideal victim, blaming the victim and personalization. 2. Trial, related to the trial by the media and the news value. 3. Post-trial developing theories about the scandal and institutional failure.
\end{abstract}

Keywords: criminology, victimology, media studies, news value.

\footnotetext{
* El presente artículo es una traducción del inglés de la tesis realizada por la autora para obtener el grado de Master of Science in Criminology and Criminal Justice en la Universidad de Edimburgo financiada por CONICYT Programa de Capital Humano Avanzado Magíster Becas Chile 2017 - folio 73180145.
} 


\section{Polít. Crim. Vol. 15, № 29 (Julio 2020), Art. 12, pp. 330-361 [http://politcrim.com/wp-content/uploads/2020/07/Vol15N29A12.pdf]}

\section{Introducción}

Durante la madrugada del 14 de mayo de 2016, Nabila Rifo Ruiz fue encontrada agonizando en una calle en Coyhaique, ciudad del sur de Chile. Había sido fuertemente golpeada, tenía fracturas en su cráneo y su victimario había removido violentamente sus globos oculares con una llave de auto. ${ }^{1}$

Este acto de violencia fue, desde el principio, ampliamente cubierto por la prensa nacional de Chile. ${ }^{2}$ Es posible encontrar cobertura mediática de varias fuentes desde el día siguiente en que esto ocurrió. Posteriormente, el juicio fue televisado por el Canal del Poder Judicial ${ }^{3}$ y retransmitidos por los otros canales chilenos de televisión.

Por lo tanto, la víctima, además de las consecuencias emocionales y físicas que esta agresión le produjo, tuvo que enfrentar una amplia exposición mediática de las circunstancias de su crimen y de su vida personal incluyendo la divulgación del informe forense ginecológico que fue presentado en el juicio. ${ }^{4}$ Ella también fue cuestionada antes y después del juicio debido a que cambió su versión respecto de quién fue responsable de sus lesiones. ${ }^{5}$

Esta investigación busca examinar la forma en que Nabila Rifo fue representada por los medios de comunicación como una víctima de un crimen y explicar por qué los medios cambiaron su foco de atención a medida que la investigación y el juicio se fueron desarrollando a través del método de estudio de caso. ${ }^{6}$

Se argumenta aquí que, en el reporte de noticias sobre crímenes, la imagen de la víctima y el foco de atención cambian de manera que el caso pueda mantener su valor noticioso. ${ }^{7}$ Esta investigación busca hacer este cambio evidente separando la cobertura mediática en tres etapas principales: investigación, juicio y post-juicio. Sin embargo, no solo se intenta aquí mostrar estas variaciones, sino que también explicarlas por medio de teorías criminológicas referidas a las víctimas y a los medios de comunicación. ${ }^{8}$ Esta investigación incluye una aproximación criminológica para explicar cómo los medios han construido socialmente el concepto de víctima. A través del método de estudio de caso, se explorará la relación entre víctimas y medios de comunicación. Sin embargo, el análisis estará centrado en la exposición de la víctima y cómo su representación ha fluctuado entre un apoyo incondicional reflejado en la opinión pública que condena los actos de violencia contra la mujer y un cuestionamiento sobre su vida privada y personal que fue transformada en un juicio mediático. A pesar de que grupos feministas y contra la violencia intrafamiliar han continuado dándole apoyo a la víctima, los medios de comunicación se han enfocado en ellos de

\footnotetext{
${ }^{1}$ LA TERCERA (2017b), passim.

224 HORAS (2016b), s/p; SOYCHILE (2016), s/p.

${ }^{3}$ PODER JUDICIAL TV (2017b), s/p.

${ }^{4}$ EMOL (2017a), passim.

${ }^{5}$ LA CUARTA (2016a), passim.

${ }^{6}$ GOMM (2000), passim. YIN (2009), passim.

${ }^{7}$ En inglés el concepto original utilizado por la mayoría de los autores citados es "newsworthiness".

${ }^{8}$ CHIBNALL (1977), passim; CHRISTIE (1986), pp. 17-30. Greer y McLaughlin han desarrollado diversos estudios referidos a los medios de comunicación y la criminología desarrollando los conceptos de juicio mediático (Trial by Media) y justicia mediática (Media Justice), siendo varios de sus artículos utilizados en esta investigación. Otra autora destacada en esta materia es Yvonne Jewkes, particularmente hago referencia aquí a su libro JEWKES (2005), passim.
} 
manera intermitente, perdiendo visibilidad. Esta pérdida de valor de ciertos aspectos de las noticias es determinada por lo que se considera como "valor noticioso" por aquellos que construyen las noticias sobre crímenes. ${ }^{9}$

También, esta información contradictoria ha sido proyectada por los medios como una crítica hacia el Poder Judicial, retratando el escándalo ${ }^{10} \mathrm{y}$ fallo institucional. ${ }^{11}$ Por una parte, se muestra la reducción que hizo la Corte Suprema a la sentencia del agresor como un acto que favorece la impunidad, implicando que el ofensor debió tener una sentencia más alta. Por otra parte, se muestra que hay dudas respecto de la prueba presentada por la Fiscalía y que esto influyó en el resultado del juicio, implicando que el procedimiento estuvo viciado y que la Fiscalía no siguió todas las líneas de investigación ya que la víctima podría estar encubriendo a un tercero involucrado.

Estas representaciones contradictorias, entre creerle a la víctima y no creerle, han sido justificadas a través del "valor noticioso de la historia". Este "no es un proceso aleatorio o personal". ${ }^{12} \mathrm{Al}$ contrario, es un proceso complejo en el cual "editores y periodistas seleccionan, producen y presentan noticias de acuerdo con una serie de criterios profesionales que son usados como punto de referencia". ${ }^{3}$

A través del valor noticioso, la exposición de la víctima fue justificada. No obstante, la exposición de la privacidad de la víctima alcanzó un punto en que una gran parte de la opinión pública se volvió en contra de la prensa causando incluso la renuncia de aquellos que tomaron la decisión editorial. La investigación tratará de dar una mirada profunda a los valores mediáticos, las representaciones mediáticas y las respuestas del público en este caso a través de teorías criminológicas y de medios; todo esto con la ventaja de dar una aproximación original usando el método de estudio de caso y entrando en el contexto de los medios de comunicación chilenos desde una perspectiva criminológica inexplorada. Sin embargo, se admite como limitación que no se ha abordado directamente con una perspectiva de género puesto que el foco se ha puesto en la teoría criminológica.

La estructura del artículo y el análisis de caso están divididos en dos partes. La primera parte, guiará al lector a través de la metodología utilizada, las preguntas de investigación, el contexto y las teorías criminológicas sobre medios de comunicación y víctimas. La segunda parte está centrada en el análisis del caso y su representación mediática.

Para llevar a cabo un análisis longitudinal a través del tiempo, éste será dividido en tres etapas principales: investigación, juicio y post-juicio. Esto porque, en cada etapa, la exposición de la víctima alcanzó distintos niveles. Los temas claves analizados en cada etapa serán: la representación mediática de la víctima (esto significa entender cómo los medios retrataron la imagen general de la víctima); los valores noticiosos considerados en cada etapa; y la respuesta del público a estas representaciones.

\footnotetext{
${ }^{9}$ Se desarrollará en paralelo tres explicaciones para reconocer el valor noticioso presentadas por CHIBNALL (1977), passim; JEWKES (2010), passim; JEWKES (2015), passim; KATZ (1987), passim.

${ }^{10}$ GREER y MCLAUGHLIN (2017), pp. 112-132.

${ }^{11}$ GREER y MCLAUGHLIN (2012b), pp. 274-293.

12 JEWKES (2015), p 45. Traducción por la autora de este artículo.

13 JEWKES (2015), p 45. Traducción por la autora de este artículo.
} 
La primera etapa trata de las representaciones iniciales de la víctima incluyendo el hecho de nombrarla y culparla y la dualidad entre la víctima ideal y la víctima indigna. La segunda etapa está relacionada con el desarrollo del juicio, particularmente los comentarios de los programas de televisión que llevaron a un juicio mediático, la divulgación del informe ginecológico, y las declaraciones públicas que la culpaban. La tercera etapa analiza la cobertura mediática que se produjo después del juicio incluyendo un programa de televisión llamado "Las dudas en el caso de Nabila Rifo". ${ }^{14}$ Este fue un programa especial que levantó dudas respecto de la evidencia del Ministerio Público, situación que no se ha visto en ningún otro caso. Aquí también se incluye el recurso presentado ante la Corte Suprema y las demandas de la víctima en contra de ciertos programas de televisión y del agresor. Finalmente, el artículo termina con un análisis y una comparación de las etapas para entender el retrato de la víctima y su relación con el contexto teórico criminológico más amplio sobre representación mediática que fue presentada en la primera parte.

\section{Metodología, Contexto Mediático y Antecedentes Teóricos}

\subsection{Métodos y Preguntas de Investigación}

El análisis sustantivo es desarrollado a través del método de estudio de caso. Este estudio sigue un diseño de investigación cualitativo y toma este método para entender la representación mediática de víctimas en Chile, con un análisis en profundidad de representaciones particulares de la víctima de este caso después de la ocurrencia de hechos importante en el proceso. Este crimen se transformó en un evento de gran relevancia cubierto por la prensa y llevado al público por todos los medios de comunicación en Chile. El objetivo principal al usar este método es la posibilidad de mostrar, en un contexto concreto y específico, cómo una víctima puede ser representada en Chile, usando teorías criminológicas y de medios como antecedente.

La elección del caso de Nabila Rifo está basado en la relevancia mediática que presenta puesto que los reportes periodísticos fueron mantenidos por más de dos años y cubrieron distintos aspectos del caso, incluyendo procesos judiciales y la vida personal de la víctima. Además, este caso presenta características que lo hacen singular, puesto que fue el único juicio que ha sido completamente transmitido con cobertura en vivo de los testimonios de las víctimas y testigos. Después de este caso, las transmisiones fueron limitadas debido a las repercusiones que causó la exposición que tuvieron los que participaron en este caso.

Dentro del campo de la criminología, es posible encontrar ejemplos donde el método de estudios de caso ha sido una valorada fuente de conocimiento. Uno de los casos más emblemáticos es el que Cohen relata en "Demonios Populares y Pánicos Morales" 15 cuyo análisis constituye la fundación de toda la teoría referida al pánico moral. Otro ejemplo es el trabajo de Hall et al., ${ }^{16}$ donde ellos describen la forma en que los medios de comunicación cubren los asaltos como un fenómeno creciente a través de un estudio de caso.

\footnotetext{
1424 HORAS (2017), passsim

${ }^{15}$ COHEN (2017), passim.

${ }^{16}$ HALL et al.(1978), passim.
} 
Según Yin ${ }^{17}$ este método es apropiado cuando un investigador no requiere control de los eventos, cuando está enfocado en eventos contemporáneos y cuando es necesario responder preguntas de investigación explicativas (cómo y por qué).

Todas estas condiciones se cumplen en esta investigación porque las principales preguntas de investigación que se pretende responder son: ¿Cómo fue la víctima retratada por los medios en este caso? ¿Por qué fue retratada de esa forma? ¿Cambió la representación mediática del caso a lo largo del tiempo desde la cobertura inicial del caso en comparación a después del juicio?

El crimen presentado ha tenido la atención de los medios de comunicación en sus diferentes etapas. Estos elementos hacen apropiado el estudio de caso para ejemplificar como las teorías globales sobre víctimas pueden ser aplicadas en una situación particular y así ver más claramente el efecto que estas representaciones tienen dentro del contex to de la sociedad chilena. Lo anterior, no obsta la necesidad del desarrollo de futuras investigaciones que comparen varios casos de relevancia mediática.

\subsection{Contexto Mediático y Recolección de Datos}

La aproximación de estudio de caso es flexible, y usualmente recae en diferentes tipos de métodos de recolección de datos y de fuentes lo que permite combinar fuentes de periódicos, televisión e internet.

Los datos han sido recolectados de medios de comunicación con alcance nacional en Chile que tiene formalmente la libertad de prensa, la que sin embargo, ha sido criticada por su alto nivel de concentración en los medios de comunicación y por su falta de pluralismo. ${ }^{18}$

Se revisaron las bases de datos de cuatro periódicos con la mayor circulación a nivel nacional, ${ }^{19}$ tanto en papel como en formato digital. Dos de ellos, Las Últimas Noticias (en adelante, "LUN") y El Mercurio (en adelante, "EMOL") pertenecen a la sociedad El Mercurio S.A.P. Esta sociedad también maneja veinte periódicos regionales que están agrupados en internet a través del sitio web de noticias Soychile. Ellos también controlan una imprenta y estaciones de radio. Desde su creación en 1900, la compañía ha pertenecido a la familia Edwards, actualmente la quinta generación tiene a cargo la administración. Esta compañía ha sido cuestionada debido a que se ha comprobado que la CIA de Estados Unidos la financió con el objetivo de desestabilizar el gobierno de Salvador Allende y luego apoyó el golpe de estado de $1973 .{ }^{20}$ Los otros dos periódicos, La Tercera (en adelante, LT) y La Cuarta (en adelante, LC) son parte del Grupo Copesa. Este grupo de medios de comunicación también administra estaciones de radio y revistas. El empresario chileno, Álvaro Saieh es dueño del $83.33 \%$ del grupo. Él también es dueño de negocios de bienes raíces, financieros y de retail y es considerado uno de los once chilenos billonarios. ${ }^{21}$

\footnotetext{
17 YIN (2009), p. 8

${ }^{18}$ LANZA (2017), passim.

${ }^{19}$ VALIDA (2017), passim.

${ }^{20}$ US DEPARTMENT OF STATE - FREEDOM OF INFORMATION ACT. (1973), passim.

${ }^{21}$ FORBES (s/f), passim.
} 


\section{Polít. Crim. Vol. 15, № 29 (Julio 2020), Art. 12, pp. 330-361 [http://politcrim.com/wp-content/uploads/2020/07/Vol15N29A12.pdf]}

Dentro de estas dos empresas están concentrados el $80 \%$ del público y un $83 \%$ de la publicidad en periódicos. ${ }^{22}$ Dentro de este contexto mediático, EMOL y LT tienen un discurso de noticias formal y serio mientras que LUN y LC pueden ser considerados como prensa más sensacionalista y popular. ${ }^{23}$ Los datos fueron obtenidos sistemáticamente desde sus páginas oficiales. ${ }^{24}$

También la cobertura de los canales de televisión que tienen alcance nacional fue considerada: Mega, Chilevisión (en adelante, "CHV"), Televisión Nacional de Chile (en adelante, "TVN") y Canal 13 (en adelante, "C13"). Estos cuatro canales cubren el 91\% del público y un 87\% de la inversión en publicidad en televisión. ${ }^{25}$ TVN está dentro de la categoría de empresas del Estado. Esto significa que pertenece al Estado, pero su administración se maneja como una empresa privada y depende del financiamiento a través de la publicidad privada. ${ }^{26} \mathrm{TVN}$ también tiene un canal asociado llamado 24 Horas $^{27}$ que está completamente dedicado a presentar noticias. Los otros tres canales de televisión son privados y pertenecen a distintos grupos de inversión. Mega y su área de noticias AhoraNoticias (en adelante, "AN") pertenece al Grupo Bethia. Ellos también controlan otras compañías agrícolas, de transporte y distribución y tienen inversiones en retail, aerolíneas, servicio sanitarios y administradoras de salud ${ }^{28}$. CHV fue controlado originalmente por la Universidad de Chile, pero ahora los dueños son el grupo internacional Time-Warner a través de su rama Latinoamericana Turner Broadcasting System Latin America. ${ }^{29} \mathrm{C} 13$ pertenecía inicialmente a la Pontificia Universidad Católica de Chile, pero desde noviembre de 2017 pertenece totalmente a Andrónico Luksic quien también es dueño de bancos y de compañías agrícolas, industriales y mineras. ${ }^{30} \mathrm{C} 13$ también tiene un área dedicada exclusivamente a las noticias llamado Tele13 (en adelante, "T13").

Los datos e información del juicio fueron obtenidos desde Poder Judicial TV (en adelante, PJUDTV); este es un canal de televisión completamente administrado por el Poder Judicial. La información fue recolectada sistemáticamente desde las páginas webs de las televisoras ${ }^{31}$ y de sus

\footnotetext{
${ }^{22}$ CONSEJO NACIONAL DE TELEVISIÓN (2015), passim.

${ }^{23}$ BIGNELL (2002), passim.

${ }^{24}$ Las páginas web sistemáticamente revisadas de los periódicos fueron: EMOL, En http://www.emol.com/. LA CUARTA, En http://www.lacuarta.com/. LA TERCERA, En http://www.latercera.com/. LAS ULTIMAS NOTICIAS, En www.lun.com. SOYCHILE, En http://www.soychile.cl/.

${ }^{25}$ CONSEJO NACIONAL DE TELEVISIÓN (2015), passim.

${ }^{26}$ TVN está regulado por la Ley 19.132 y posee un carácter mixto. Pertenece al Estado, los miembros de su directorio son nombrados por el Presidente de la República y el Senado y sus ganancias pasan a formar parte del patrimonio fiscal. Sin embargo, en cuanto a sus actividades financieras y tributarias se rige por las normas de las Sociedades Anónimas y sus empleados se rigen por el Código del Trabajo. Hasta mayo del año 2018, cuando entró en vigencia la ley 21.085 que modificó la ley 19.132, TVN solo podía obtener financiamiento estatal en las mismas condiciones que lo haría una empresa privada, es decir, si recibía aportes del Estado de Chile lo hacía en la misma forma que los otros canales de televisión privados. Actualmente, TVN aún debe obtener su financiamiento "a condiciones de mercado y de manera transparente y competitiva", pero la Ley de Presupuestos puede considerar aportes o transferencias a TVN. ${ }^{27}$ En http://www.24horas.cl/ [Visitado el 11 .06. 2018].

${ }^{28} \mathrm{En}$ http://www.bethia.cl/\#empresas-que-gestionamos [Visitado el 12.07.2018].

${ }^{29}$ En: https://www.warnermediagroup.com/newsroom/press-releases/2010/08/25/turner-broadcasting-system-inc-toacquire-chilevisi-n [Visitado el 12.07.2018].

${ }^{30}$ CONSEJO NACIONAL DE TELEVISIÓN (2015), passim.

${ }^{31}$ Los sitios web oficiales de los canales de televisión desde los que se extrajo sistemáticamente la información son: CANAL 13, en: http://www.13.cl/. CHILEVISION, en: http://www.chilevision.cl/. MEGA, en: http://www.mega.cl/home/. PODER JUDICIAL TV, en: http://www.poderjudicialtv.cl/. TELE 13, en: http://www.t13.cl/. TELEVISION NACIONAL DE CHILE, 24 horas, en: http://www.24horas.cl/. TELEVISION
} 
canales oficiales de YouTube $^{32}$ Las fuentes teóricas están en inglés y fueron traducidas directamente por la investigadora en este artículo.

\subsection{Antecedentes Teóricos}

Las víctimas han ido ganando una posición central dentro del sistema de justicia criminal ${ }^{33}$; hay una preocupación creciente respecto de ellas en todo el mundo. ${ }^{34}$ Garland ${ }^{35}$ llama a este proceso "el regreso de la víctima" donde "las víctimas deben ser protegidas, sus voces deben ser escuchadas, su memoria respetada, su ira expresada y sus miedos atendidos". ${ }^{36}$ Los medios de comunicación no están ajenos a este fenómeno. Un análisis extendido de contenido histórico sobre la representación de los crímenes en el cine, la televisión y los periódicos desde 1945 a 1991 en Gran Bretaña ${ }^{37}$ concluyó que los mayores cambios en la representación de los medios están en la forma en que se retrata a las víctimas ya que progresivamente "las víctimas se han movido desde un rol vago y puramente funcional en las narrativas del crimen a una posición esencial". ${ }^{38}$

Esta nueva posición de las víctimas también hace más evidente una reacción negativa hacia ellas: la culpabilidad. Culpar a las víctimas surge desde la creencia que:

"si ellas pudieran haberse protegido a sí mismas, si pudieron haber ejercido cierto control sobre su destino, y no lo hicieron, entonces han fallado de alguna manera. En consecuencia, han sido agentes cuyo actuar y no actuar marcaron su propio destino". ${ }^{39}$

No obstante, creer esto es asumir que podemos controlar todos los eventos en nuestra vida, lo que se aleja mucho de la realidad. Por esta misma razón, esta posición ha sido criticada, sin embargo, esta no ha dejado de existir. Es común encontrar comentarios de esta naturaleza en los medios de comunicación y las redes sociales. ${ }^{40}$ Culpar a la víctima continúa siendo una posición dominante en casos de violaciones ${ }^{41}$ y en casos de violencia doméstica ${ }^{42}$ incluso en países europeos que tienen una mayor equidad de género. ${ }^{43}$

En oposición a la percepción negativa de la víctima, es posible percibir una reacción de deferencia hacia ellas; la idea de que las víctimas son "personas virtuosas que están más allá de cualquier

NACIONAL DE CHILE, en: http://www.tvn.cl/.

${ }^{32}$ CANAL 13, YouTube Channel, en: https://www.youtube.com/user/canal13. CHILEVISION, YouTube Channel, en https://www.youtube.com/user/chvtevedeverdad. MEGA, YouTube Channel, en https://www.youtube.com/user/programasmega. TELEVISION NACIONAL DE CHILE, YouTube Channel, en: https://www.youtube.com/user/tvn.

${ }^{33}$ DUCE et al. (2014), pp.739-815.

${ }^{34}$ HALL (2017), passim.

ROCK (1990), passim.

35 GARLAND (2001), passim.

${ }^{36}$ GARLAND (2001), p. 11. Traducción por la autora de este artículo.

${ }^{37}$ REINER et al. (2001), pp. 174-194.

${ }^{38}$ REINER et al. (2001), p. 183. Traducción por la autora de este artículo.

${ }^{39}$ GOVIER (2015), p.6. Traducción por la autora de este artículo.

40 TELEVISIÓN NACIONAL DE CHILE (2017a), passim.

${ }^{41}$ BIENECK y KRAHÉ (2011), pp. 1785-1797.

${ }^{42}$ MEYERS (1994) pp. 47-63; MEYERS (1997), passim.

${ }^{43}$ GRACIA (2014), pp. 380-381. 


\section{Polít. Crim. Vol. 15, № 29 (Julio 2020), Art. 12, pp. 330-361 [http://politcrim.com/wp-content/uploads/2020/07/Vol15N29A12.pdf]}

crítica". ${ }^{44}$ Esta actitud hacia las víctimas es relevante en nuestra sociedad y este concepto responde la pregunta respecto a cómo se representa a las víctimas. Existen muchos grupos de apoyo que constantemente generan campañas en favor de las víctimas y que tratan de dar visibilidad a sus problemas. Este factor es importante cuando se trata de conectar la victimología con los medios de comunicación. La deferencia se ha transformado en un aspecto clave en el retrato mediático de las víctimas porque trae implícito dos puntos que son atractivos para el público: inocencia y sufrimiento. ${ }^{45}$ Esta necesidad ha sido tomada por los medios de comunicación a veces asumiendo un rol de protección hacia las víctimas con eslogan del tipo "justicia para" y otras veces con un rol de denuncia en contra de la ineficiencia de la justicia de compensar a las víctimas.

Esta nueva posición de las víctimas no es equitativa. No todas las víctimas han asumido un rol central. Christie ${ }^{46}$ describe las categorías de víctimas que realmente les interesan a los medios de comunicación como una víctima ideal, esto es:

"una persona o categorías de personas quienes - cuando son golpeados por un crimen - más fácilmente se les da el estatus completo y legítimo de ser una víctima". ${ }^{47}$

Él también describe los atributos de una víctima ideal: usualmente la víctima es una mujer, es débil, está llevando a cabo un proyecto respetable y se encuentra en una situación donde no es posible de ser culpada. ${ }^{48}$ En contraste, el ofensor es grande, malo y éste no tiene ninguna relación o vínculo con la víctima. ${ }^{49}$ Este último aspecto significa que estas categorías no pueden ser aplicadas a las víctimas de violencia intrafamiliar y que las víctimas de este tipo de crímenes, especialmente las esposas, no entran fácilmente dentro de la categoría de víctima ideal.

Desde un contexto más amplio, la representación mediática de las mujeres no es sólo sobre víctimas ideales y no ideales; también ha sido descrita como dicotómica y polarizada en otros aspectos generalmente retratándolas como promiscua/ desviada o virgen/ frígida ${ }^{50}$ o como Madonna/ prostituta. ${ }^{51}$ Esto es especialmente relevante cuando nos referimos a víctimas mujeres porque condiciona la respuesta del público entre culpa y deferencia. Benedict ${ }^{52}$ define esta dicotomía en las representaciones mediáticas de mujeres víctimas de delitos sexuales usando dos conceptos clave: la versión vampira:

"la mujer que, por su apariencia, comportamiento o por su moralidad relajada lleva al hombre a tal extremo de lujuria que se vio obligado a cometer el crimen",53

y la versión virginal:

${ }^{44}$ GOVIER (2014), p. 10. Traducción por la autora de este artículo.

${ }^{45}$ GOVIER (2014), passim.

${ }^{46}$ CHRISTIE (1986), passim.

${ }^{47}$ CHRISTIE (1986) p. 18. Traducción por la autora de este artículo.

${ }^{48}$ CHRISTIE (1986), p. 19.

${ }^{49}$ CHRISTIE (1986), p. 19.

${ }^{50}$ JEWKES (2004), p. 135.

${ }^{51}$ NAYLOR (1995), pp. 77-95.

${ }^{52}$ BENEDICT (1992), passim.

${ }^{53}$ BENEDICT (1992), p. 23. Traducción por la autora de este artículo. 


\section{MARDONES, Daniela: "Representación mediática y cobertura de los medios de las mujeres víctimas de violencia intrafamiliar en Chile: El caso de Nabila Rifo".}

"el hombre, un monstruo pervertido y depravado, mancilló a la inocente víctima, quien es ahora una mártir de las falencias de la sociedad". ${ }^{4}$

Estas categorías, usadas para describir víctimas de violación, pueden ser usadas en el contexto de violencia doméstica en contra de las mujeres especialmente considerando que, en la cultura chilena, la violencia en contra de las mujeres se inserta dentro del contexto del machismo ${ }^{55} \mathrm{y}$, entendiendo éste como masculinidad asertiva o agresiva, está relacionado al patriarcado hegemónico y a ideas de desigualdad de género que están incrustadas en las diversas culturas latino americanas. ${ }^{56}$

El análisis de las interrelaciones entre la violencia doméstica y el machismo en la representación mediática dentro del contexto de los estudios de género escapa al ámbito de este estudio criminológico. Sin negar la relevancia de estos temas y la necesidad de dar mayor profundidad al rol del género dentro del contexto de la violencia intrafamiliar, se limitará aquí al estudio del interés noticioso y valor periodístico ${ }^{57}$ en los estudios de medios de comunicación y su representación de los crímenes priorizando la victimología en general.

En consecuencia, la creciente preocupación por las víctimas y el rechazo hacia el machismo han sido recogidos por los medios haciéndolo parte de su interés noticioso. Galtung y Ruge ${ }^{58}$ fueron pioneros en la descripción de la forma de medir el interés noticioso de un hecho con una lista de valores periodísticos. Sin embargo, para entender este concepto es necesario referirse a tres autores claves que tomaron la noción de interés noticioso y lo expandieron en su desarrollo conceptual: Chibnall, ${ }^{59}$ Jewkes $^{60}$ y Katz. ${ }^{61}$ Ellos desarrollaron un análisis sobre cuáles eran los atributos que un "hecho" requiere para ser considerado como una "noticia". Para hacerlo, describieron categorías que son generalmente usados por los medios de comunicación para desarrollar sus líneas editoriales. Chibnall ${ }^{62}$, se refiere a estas categorías como imperativos profesionales que están implícitos en la construcción de las noticias. Así, él definió ocho imperativos: inmediación, dramatización, personalización, simplificación, excitación, convencionalismo, acceso estructurado y novedad ${ }^{63}$ y concluye que ésta no es una lista exhaustiva y que todos estos imperativos pueden o no estar presentes y también presentarse de manera contradictoria. Sin embargo, todos los periodistas habrían internalizado estas categorías sin necesidad de hacerlas explícitas.

Desde esta estructura, Jewkes, ${ }^{64}$ extiende el concepto de imperativos a valores periodísticos y considera doce estructuras dentro de estos valores: umbral, predictibilidad, simplificación, individualismo, riesgo, sexo, celebridad o persona de estatus alto, proximidad, violencia o

${ }^{54}$ BENEDICT (1992), p. 23. Traducción por la autora de este artículo.

${ }^{55}$ CLAY (2011), passim.

${ }^{56}$ LATIN AMERICAN AND CARIBBEAN WOMEN'S HEALTH NETWORK (2008) pp. 46-49.

${ }^{57}$ Los conceptos "newsworthiness" y "news value" han sido traducidos aquí como interés noticioso y valor periodístico respectivamente.

${ }^{58}$ GALTUN y RUGE (1973), pp. 62-73.

${ }^{59}$ CHIBNALL (1997), passim.

${ }^{60}$ JEWKES (2010), pp. 215-227. JEWKES (2015), passim.

${ }^{61}$ KATZ (1987), pp. 47-75.

${ }^{62}$ CHIBNALL (1997), passim.

${ }^{63}$ CHIBNALL (1997), passim.

${ }^{64}$ JEWKES (2004), passim; JEWKES (2015), passim. 


\section{Polít. Crim. Vol. 15, № 29 (Julio 2020), Art. 12, pp. 330-361 [http://politcrim.com/wp-content/uploads/2020/07/Vol15N29A12.pdf]}

conflicto, espectáculo visual o imagen gráfica, niños e ideología conservadora y desviación política. ${ }^{65}$

El umbral ${ }^{66}$ es un asunto clave para ver el potencial de la noticia; la historia debe tener cierto nivel de drama para ser considerada y luego debe seguir creando nuevos umbrales para mantener la historia viva. ${ }^{67} \mathrm{El}$ caso estudiado aquí cumple con este criterio. En primer lugar, la historia fue percibida como importante porque la idea de que alguien saque los ojos de su pareja es extremadamente violenta y, al mismo tiempo, poco frecuente. En segundo lugar, porque la noticia ha continuado generando nuevos umbrales que le permitieron crecer en relevancia al punto de que, en la etapa de post juicio, tuvo cobertura internacional incluso en inglés. ${ }^{68}$

Finalment, Katz ${ }^{69}$ ofrece una perspectiva diferente. Según él, el umbral y las otras categorías no son suficientes para explicar por qué una noticia puede mantener su valor periodístico más allá del momento en que se generan los eventos y luego persistir por un tiempo indeterminado o volver regularmente a las noticias. Esto es porque, para él, las noticias sobre crímenes no son inesperadas, al contrario, ellas vienen a confirmar situaciones que son asumidas por el público como verdaderas y comunes (que los políticos son corruptos, que las empresas contaminan o, como en este caso, que los hombres golpean a las mujeres). Entonces su foco está en quien recibe las noticias y no en quien las escribe.

A pesar de estas diferencias, esto autores revelan un aspecto fundamental del tema: que existen características esenciales que hacen que un acto criminal tenga un valor periodístico y que éste no está fijo en el tiempo, por el contrario, varía de acuerdo con los intereses de los periodistas y del público. Esta noción de variabilidad es muy relevante en este estudio porque se mostrará como el mismo acto criminal fue variando en su valor noticioso y diferentes aspectos de este fueron relevantes en cada etapa del proceso.

La variabilidad también se ve reflejada en la respuesta del público que se encuentra vinculada al llamado juicio mediático y escándalo institucional. El juicio mediático ha sido largamente estudiado por Greer y McLAughlin. Ellos lo definieron como

"una forma de justicia populista en el cual individuos e instituciones son juzgados por la intermediada "corte de la opinión pública". ${ }^{70}$

Este juicio mediático se vuelve evidente cuando un juicio criminal es transmitido en vivo puesto que da la posibilidad de especular con respecto al resultado del mismo y la gente puede juzgar incluso antes de tener todos los hechos del caso.

\footnotetext{
65 JEWKES (2015), p. 49-70.

${ }^{66}$ La categoría del umbral ("threshold” en inglés) dice relación con la acepción de umbral como la magnitud o la intensidad que debe excederse para que una determinada reacción ocurra.

${ }^{67}$ JEWKES (2015), p. 49.

${ }^{68}$ BBC UK NEWS (2017), s/p; INDEPENDENT (2017), s/p; MIRROR (2017), s/p.

${ }^{69} \mathrm{KATZ}$ (1987), passim.

${ }^{70}$ GREER y MCLAUGHLIN (2017), p.268. Traducción por la autora de este artículo.
} 
Sin embargo, la opinión pública no es solo receptora de la información entregada por los medios. ${ }^{71}$ La participación activa se ha transformado en una forma común de conectar con los medios de comunicación especialmente después de la masificación del acceso a internet. Esta interacción va desde opiniones especulativas en las secciones de comentarios hasta compartir juicios respecto de la inocencia o culpabilidad del acusado. ${ }^{72}$ Esto también ha generado la habilidad del público de juzgar a los propios medios de comunicación. El público puede comentar respecto de la relevancia o no de cierta información y respecto de la forma en que los medios se refieren a un hecho en particular.

Esta capacidad de interactuar con las noticias también ha llevado a un tipo particular de respuesta del público: el escándalo. Según Thompson, ${ }^{73}$ el escándalo se refiere a acciones o circunstancias que se caracterizan por lo siguiente:

"1. Su ocurrencia o existencia envuelve transgresiones de ciertos valores, normas o códigos morales. 2. Son conocidos o se cree fuertemente que ocurrirán por individuos que no son los directamente relacionados (...). 3. Algunos no participantes desaprueban las acciones o eventos y pueden estar ofendidos (...). 4. Algunos no participantes expresan su desaprobación denunciando públicamente (...). 5. La revelación y condena de las acciones o eventos puede dañar la reputación de los individuos responsables de ellos (...)." ${ }^{.74}$

El aspecto fundamental del escándalo radica en la transgresión de códigos éticos o morales. Estos pueden ser personales (como el adulterio), pero también pueden ser institucionales. Los escándalos institucionales resultan desde una "norma escándalo-sensible que es una regla, convención y procedimientos que gobiernan la búsqueda y el ejercicio del poder político". ${ }^{75}$ Este tipo de escándalo no es solo manejado por la prensa, sino que también se transforma en un arma de presión de grupos políticos y sociales que quieren empujar sus propias agendas. Greer y McLaughlin van más allá y en un reciente artículo ${ }^{76}$ afirman que:

"el escándalo se ha vuelto un mecanismo clave usado por los medios de comunicación noticiosos, grupos de presión y movimientos sociales para demandar consultas e investigaciones hacia presunta corrupción, incompetencia e inmoralidad". ${ }^{77}$

Ellos concluyen que "la cacería de escándalos" es un "modelo de negocios" para los medios de comunicación y "el fracaso institucional se ha convertido en el tropo explicativo"78. El cambio en la opinión pública causado por el escándalo institucional afecta la confianza que la gente tiene en la legitimidad institucional. No puede haber escándalo institucional si la gente no tiene dudas respecto de la legitimidad de las instituciones. ${ }^{79}$ Los hechos deben entrar en lo que ya tienen en sus mentes. Esto se conecta con el concepto que Katz ${ }^{80}$ tiene de valor periodístico: las noticias

${ }^{71}$ TALBOT (2007), passim.

${ }^{72}$ GREER (2017), p. 269

${ }^{73}$ THOMPSON (1997), pp. 34-64.

${ }^{74}$ THOMPSON (1997), p. 39. Traducción por la autora de este artículo.

75 THOMPSON (1997), p. 40. Traducción por la autora de este artículo.

${ }^{76}$ GREER (2017b), passim.

${ }^{77}$ GREER (2017b), p. 113. Traducción por la autora de este artículo.

${ }^{78}$ GREER (2017b), p. 128. Traducción por la autora de este artículo.

${ }^{79}$ FINE (1997) pp. 297-323.

${ }^{80}$ KATZ (1982), passim. 


\section{Polít. Crim. Vol. 15, № 29 (Julio 2020), Art. 12, pp. 330-361 [http://politcrim.com/wp-content/uploads/2020/07/Vol15N29A12.pdf]}

confirman los miedos y prejuicios que el público ya posee y estos aumenta en la medida que las noticias constantemente se enfocan en las mismas áreas.

En la próxima sección se verá cómo estas categorías conceptuales pueden ser aplicadas a las diferentes etapas estudiadas de acuerdo con las variaciones que la representación mediática tuvo durante los años de cobertura noticiosa de este evento. Para hacer esto es necesario describir la representación mediática en diferentes etapas del proceso y, usando una aproximación criminológica, comparar los diferentes enfoques que los medios de comunicación han tenido de acuerdo con las situaciones específicas que fueron destacadas en cada etapa.

\section{Estudio de Caso}

\subsection{Primera Etapa - Investigación: de nombrar a la víctima a culpar a la víctima}

Durante los primeros reportes de este crimen, la prensa mostró una simpatía incondicional hacia la víctima, especialmente revelando detalles de denuncias previas y problemas de violencia intrafamiliar con el agresor. Hay tres aspectos centrales que los medios enfatizaron dentro de las primeras horas después de ocurrido en evento: género, violencia y ubicación. En reiteradas ocasiones la prensa usó la palabra "mujer" dando énfasis a los problemas de género y la violencia del acto utilizando palabras como "mujer violentada", 81 "violencia intrafamiliar", 82 "brutalmente" "83; "brutal agresión", ${ }^{84}$ "salvaje ataque". ${ }^{85}$ La palabra Coyhaique, nombre de la ciudad donde ocurrieron los eventos, se repitió constantemente. Esto porque la ciudad tiene menos de 60.000 habitantes ${ }^{86} \mathrm{y}$, usualmente, no ocurren estos actos de connotación tan violenta. Por lo tanto, el interés noticioso de este caso estuvo inicialmente centrado en la violencia de género y la ubicación. Sin embargo, debe considerarse que "los eventos no entran en las noticias solo por ocurrir, no importa cuán frenéticamente". ${ }^{87}$ Según las categorías de Jewkes ${ }^{88}$ los criterios de umbral y violencia se cumplen aquí; este acto furioso trascendió la prensa local y fue proyectado nacionalmente. También es posible ver el valor de la simplificación al reducir el crimen a tres temas (violencia, género y lugar).

Estas categorías están directamente relacionadas con la visión de la víctima ideal. El concepto de Christie $^{89}$ asume que la víctima es inocente y emocional y físicamente vulnerable, lo que calza perfectamente con la idea de una mujer de una pequeña ciudad del sur que fue violentamente atacada por un ofensor desconocido sin motivo aparente. Sin embargo, estas características distintivas del caso fueron rápidamente olvidadas en la medida que el nombre de la víctima empezó a tener toda la atención. La cobertura mediática fue personificada incluyendo el nombre de la víctima hasta el punto en que su nombre ${ }^{90}$ propio se volvió conocido sin necesidad de mayores

\footnotetext{
81 TELE 13 (2016a), s/p.

8224 HORAS (2016b), s/p.

8324 HORAS (2016d), s/p.

${ }^{84}$ CHILEVISION (2016a), s/p.

${ }^{85}$ LA CUARTA (2016a), s/p.

${ }^{86}$ GOBIERNO DE CHILE (s/f), passim.

${ }^{87}$ HARTLEY (1982), p. 75. Traducción por la autora de este artículo.

88 JEWKES (2015), passim.

${ }^{89}$ CHRISTIE (1986), passim.

90 TELE 13 (2016a), passim.
} 
referencias. A diferencia de otros países, como Estados Unidos donde ha habido un largo debate respecto si se debe o no publicar el nombre de las víctimas, ${ }^{91}$ en Chile, las víctimas son usualmente llamadas por su nombre. La Ley Nº19.733 sobre Libertades de Opinión e Información y Ejercicio del Periodismo del año 2001, limita la publicación de los nombres de ofensores menores de edad y las víctimas en casos específicos. Además, esta ley solo se refiere a la publicación del nombre y no de otros aspectos como imágenes o declaraciones. ${ }^{92}$ En este caso, todas las publicaciones iniciales no incluyen el nombre de la víctima en el titular, pero lo incluyen en el desarrollo de la noticia.

El hecho de nombrar y personalizar se utiliza comúnmente en las historias noticiosas de las víctimas. ${ }^{93} \mathrm{El}$ objetivo de la personalización es hacer que el individuo aparezca como representativo de un "asunto noticioso mayor". ${ }^{94}$ La técnica de personalización al principio fue la del rol de género, representando el problema de violencia en contra de las mujeres, aunque rápidamente se movió hacia un nivel más concreto usando el nombre de la víctima directamente para representar un problema mayor. Esto se vio facilitado por el hecho de que "Nabila" no es un nombre común en Chile lo que hizo más rápido conectarlo con el caso.

La personalización no es sinónimo de individualización. En vez de eso, se trata de pertenecer a cierta categoría, ${ }^{95}$ a un grupo en particular: mujeres víctimas de violencia. Entonces, una vez que su nombre se hizo conocido fue sencillo para los medios de comunicación relacionarlo directamente con la víctima en este caso. En esta etapa, su personalidad se confunde con su rol de víctima hasta el punto en que no pueden separarse. De la misma forma, la identidad del supuesto ofensor fue rápidamente conocida y se enfatizó el hecho de que era su expareja lo que la categorizó dentro de las víctimas de violencia intrafamiliar.

En consecuencia, la respuesta del público fue de un apoyo inmediato a la víctima. Especialmente en Coyhaique donde tuvieron lugar protestas en las calles. ${ }^{96}$ La personalización de la noticia se volvió evidente ya que los manifestantes portaban carteles que decían "no más violencia contra las mujeres" y "justicia para Nabila". Al mismo tiempo, el movimiento latinoamericano en contra de la violencia de género \#Niunamenos tomó el caso como parte de su causa.

Después del ataque y debido a sus serias heridas, ella estuvo en cuidado intensivo en un hospital de Santiago durante un mes y veintiocho días. Durante este período tuvo que someterse a varias cirugías con el fin de reconstruir su rostro y para que le implantaran prótesis de globos oculares. Además, tuvo que someterse a kinesioterapia y rehabilitación psicológica debido al síndrome de estrés post traumático. El 18 de mayo de 2016, al principio de su estadía en Santiago, Michelle Bachelet, presidente de Chile en aquel momento, la visitó en el hospital. En este punto, los medios de comunicación ya estaban incluyendo el nombre de la víctima en los titulares. ${ }^{97}$ Esta visita fue interpretada posteriormente como un gesto político para empujar su agenda de género. Unos días

\footnotetext{
${ }^{91}$ BENEDICT (1992), pp. 113, 229-230.

92 LATHROP (2013) pp. 929-952.

${ }^{93}$ DE WAARDT (2016), pp. 432-450.

94 BIGNELL (2002), p. 91.

95 BIGNELL (2002), p. 92.

9624 HORAS (2016b), s/p.

9724 HORAS (2016e), s/p. TELE 13 (2016b), s/p.
} 


\section{Polít. Crim. Vol. 15, № 29 (Julio 2020), Art. 12, pp. 330-361 [http://politcrim.com/wp-content/uploads/2020/07/Vol15N29A12.pdf]}

después de esta visita, en la cuenta anual del gobierno que se realiza el 21 de mayo, Michelle Bachelet hizo referencia a este caso incluyéndolo en su discurso con el fin de apoyar cambios en la ley sobre violencia intrafamiliar y la lucha contra el machismo. ${ }^{98}$

El uso de las víctimas de delitos con el fin de apoyar agendas políticas no es algo nuevo. Jewkes ${ }^{99}$ lo categoriza como el valor noticioso de ideología conservadora y desviación política donde:

"los políticos han sido rápidos en galvanizar el apoyo de un público ansioso y temeroso (...) enfocando la atención en las desdichadas víctimas de crímenes serios y llamando por castigos más duros y más retributivos". ${ }^{100}$

No obstante, los temas han ido cambiando. En 1993, Elias escribió que el compromiso político de las víctimas estaba más relacionado con las conducciones en estado de ebriedad y las drogas pero que:

"perjuicios como la violencia doméstica y los delitos sexuales, formalmente definidos como crímenes, pero perseguimos pasivamente por las fuerzas de orden, socavan la realidad de la victimización que involucran". ${ }^{101}$

Sin embargo, en los últimos años, la violencia doméstica ha ido ganando un lugar central en las discusiones políticas y mediáticas. Desafortunadamente, la mayoría de las veces estas representaciones políticas están separadas de las solicitudes y necesidades de los grupos organizados de víctimas. ${ }^{102}$ Finalmente, Govier ${ }^{103}$ describe también el hecho de agenciar, realizado por políticos y particulares, como directamente relacionado con la justicia restaurativa. La idea principal es que la justicia debiera ser una forma de reparar y sanar a la víctima.

El apoyo político y popular proyectado en los medios de comunicación reforzó el estereotipo de víctima ideal. Como se describió anteriormente, según la categoría de Christie, ${ }^{104}$ una víctima mujer es ideal cuando no conoce a su agresor. Esta característica ha ido cambiando debido al nuevo estatus de las víctimas de violencia de género. A pesar de este cambio, en este caso, la víctima igualmente fue culpada por mantener una relación con el agresor: "las mujeres pueden protegerse a sí mismas yéndose. ¿Por qué simplemente no se van si la violencia parece surgir?”. ${ }^{105}$

Este cambio en la opinión pública se produjo durante la etapa de investigación. El ataque fue investigado durante diez meses por el Ministerio Público. Durante este período, la víctima cambió su versión de los hechos. Inicialmente, ella reconoció a su expareja como el que realizó el ataque. Después, también lo declaró así en el juicio. ${ }^{106}$ Sin embargo, en agosto del 2016 se difundió un audio donde ella hablaba con la prima del ofensor. En él, ella lo exonera de la agresión acusando

\footnotetext{
${ }^{98}$ LA TERCERA (2016a), s/p. EMOL (2017d), s/p.

99 JEWKES (2015), passim.

100 JEWKES (2015), p. 69. Traducción por la autora de este artículo.

${ }^{101}$ ELIAS (1993), passim. Traducción por la autora de este artículo.

102 GARLAND (2001), p. 11.

${ }^{103}$ GOVIER (2015), p. 12.

${ }^{104}$ CHRISTIE (1986), passim.

${ }^{105}$ CHRISTIE (1986), p. 21. Traducción por la autora de este artículo.

106 TELEVISIÓN NACIONAL DE CHILE (2017c) s/p.
} 
presiones del fiscal para declararlo culpable. ${ }^{107}$ Aunque este comportamiento es habitual en víctimas de violencia doméstica, ${ }^{108}$ no fue percibido por el público como tal y causó un quiebre de la visión que se tenía de la víctima. Aunque Michelle Bachelet y el movimiento \#Niunamenos nunca retiraron su apoyo, la prensa empezó a poner más atención en las contradicciones de la víctima y mantuvieron ese discurso a través del desarrollo del caso, lo que fue acentuado durante el juicio. ${ }^{109}$ Después de que el audio se hizo conocido, la víctima dejó de estar cerca del estereotipo de víctima ideal. Ahora era una víctima contradictoria, mentirosa y confundida.

La dualidad entre víctima digna e indigna comenzó a vislumbrarse. Aunque los medios de comunicación no usaron explícitamente esos términos,

"la víctima digna e indigna es un tema comúnmente usado en los discursos mediáticos y las ideas en torno a la moralidad son transmitidos casi inconscientemente de las páginas de los periódicos y los reportajes de televisión". ${ }^{110}$

Esto fue acentuado por una carta manuscrita que envió el sospechoso alegando su inocencia, diciendo que aún la amaba y preguntando “¿A quiénes están encubriendo?”. ${ }^{111}$ Con este cambio en la imagen pública, la víctima fue directamente culpada. La víctima es ahora presentada como la causante de su propia desgracia. El público empezó a preguntarse: ¿Por qué seguía con él si la maltrataba? ¿Por qué sigue defendiendo a su atacante? ¿Está escondiendo algo? ${ }^{112}$ El escepticismo mediático surgió ${ }^{113}$ y las causas de la violencia comenzaron a ser atribuidas a la víctima y cuando esto pasa "es más probable que los incidentes sean trivializados y vistos como entendibles o merecidos y, por lo tanto, menos injustos y más admisibles". 114

Toda esta exposición de la víctima, la culpa y la respuesta negativa que le es dada, la mantiene en un constante estado de revictimización ${ }^{115}$ lo que fue aumentando en intensidad alcanzando su punto más alto durante el juicio como se verá a continuación.

\subsection{Segunda Etapa - Juicio: Juicio Mediático y los Medios en Juicio}

El juicio oral en lo penal empezó el día 13 de marzo de 2017 y continuó hasta el 18 de abril de 2017 cuando el Tribunal Oral en lo Penal de Coyhaique declaró a Mauricio Ortega, expareja de la víctima y padre de dos de sus cuatro hijos, culpable de violación de morada, femicidio frustrado y lesiones graves gravísimas. Recibió una condena de 26 años en prisión.

El nombre de la víctima se volvió tan conocido que se transformó en una celebridad de la que todos querían saber más. ${ }^{116} \mathrm{La}$ exposición del caso por los medios de comunicación fue

\footnotetext{
10724 HORAS (2016a), s/p; EMOL (2016), s/p.

108 VICTIM WITNESS ASSISTANCE UNIT (2008), passim.

${ }^{109}$ EMOL (2016a), passim.

${ }^{110}$ MARSH y MELVILLE (2009), p 104. Traducción por la autora de este artículo.

${ }^{111}$ LA CUARTA (2016b), passim.

${ }^{112}$ La mayoría de las noticias revisadas a partir de este punto contienen comentarios que directamente culpan a la víctima de lo que pasó. A modo de ejemplo, revisar los comentarios en EMOL (2016a), passim.

113 GREER y MCLAUGHLIN (2012), pp. 395-416, p.404.

114 GRACIA (2014), p. 380. Traducción por la autora de este artículo.

115 VAN DIJK (2009) pp. 1-33.

116 JEWKES (2015), p. 57.
} 


\section{Polít. Crim. Vol. 15, № 29 (Julio 2020), Art. 12, pp. 330-361 [http://politcrim.com/wp-content/uploads/2020/07/Vol15N29A12.pdf]}

controversial y, al final, nuevas políticas tuvieron que ser implementadas para proteger a víctimas y testigos en juicios futuros. ${ }^{117}$ Durante este período, fue posible observar un juicio paralelo llevado por los medios de comunicación: mientras testigos y peritos presentaban el caso en el tribunal, los medios sometieron a un intenso escrutinio todo lo que fue dicho en el juicio, emitiendo opiniones sin conocimiento legal y sin que todos los antecedentes fueran presentados. No esperaron a ver toda la evidencia para dar un veredicto, en vez de eso, consideraban cada declaración sin análisis crítico dentro del contexto del juicio. A la audiencia se le presentó un escenario donde:

"el debido proceso y la objetividad periodística puede dar paso a la especulación sensacionalista y moralista sobre las acciones y motivos de quienes se paran como acusados en el foco de los medios de comunicación". ${ }^{118}$

En este proceso, tuvieron lugar los eventos más controversiales que involucraron a los medios de comunicación. El primero de ellos, fue la presentación de una amiga cercana del ofensor en el programa matinal Muy Buenos Días de TVN el día 06 de abril de 2017. ${ }^{119}$ Ella estaba en Coyhaique y fue entrevistada en vivo por un periodista que se encontraba en el lugar mientras el resto de los panelistas del programa estaban en Santiago siguiendo la entrevista y realizando preguntas. En medio de la entrevista, ella declaró, "Yo creo que ella se lo buscó (...) ella es grandecita y sabía con qué persona estaba y, bueno, si ella no quería estar más con él ¿por qué no se separó?”. Después de esta dura declaración, el periodista preguntó “¿Tú crees que la culpa de la agresión es de ella?" y ella respondió "sí". ${ }^{120}$ Esta explícita atribución de culpa hacia la víctima causó la perplejidad de los comentaristas quienes comenzaron a persuadirla para que cambie su opinión hasta que uno de los anfitriones se puso a cargo de la situación y decidió cortar la entrevista. El canal de televisión dijo que su intención era tener una visión objetiva del sujeto por lo que tenían que incluir a alguien que apoyara al acusado, pero que nunca esperaron ese tipo de declaraciones.

La auto censura en una transmisión en vivo no es común. Especialmente porque "los códigos de las noticas de objetividad y balance - de tener los dos lados de la historia - también niegan la seriedad del crimen". ${ }^{121}$ Sin embargo, el medio determinó una posición clara respecto de que no todas las declaraciones son tolerables en el contexto de la victimización. Esta muestra de deferencia ${ }^{122}$ hacia la víctima prueba la intención de los medios de dar declaraciones juzgando y de tener su propio juicio paralelo.

En la medida que el juicio avanzaba y más testigos presentaban su testimonio, aspectos que distanciaban a la víctima del ideal fueron revelados: había una fiesta en su casa; estuvo bebiendo alcohol con el perpetrador; expuso a sus hijos a la violencia; durante la fiesta se levantó la blusa y mostró sus senos. Además, la teoría de la defensa era que el atacante fue otro hombre. Este hombre sería uno con el quien ella mantenía una relación y supuestamente lo estaba encubriendo. Por esta razón, el defensor abiertamente le preguntó por su vida sexual hasta el punto en que ella preguntó

\footnotetext{
117 EMOL (2017f), s/p.

118 GREER y MCLAUGHLIN (2011) pp. 23-46, p.27. Traducción por la autora de este artículo.

119 TELEVISIÓN NACIONAL DE CHILE (2017b), s/p.

120 TELEVISIÓN NACIONAL DE CHILE (2017b), ver minuto 21:58 en adelante.

${ }^{121}$ MEYERS (1994), p. 56. Traducción por la autora de este artículo.

122 GOVIER (2015), passim.
} 


\section{MARDONES, Daniela: "Representación mediática y cobertura de los medios de las mujeres víctimas de violencia intrafamiliar en Chile: El caso de Nabila Rifo".}

“QQué tiene que ver mi vida sexual con lo que me pasó?”. ${ }^{23}$ Todo esto fue presentado en la televisión abierta a nivel nacional.

Después de que surgieron las dudas respecto de su comportamiento sexual, otro tipo de valor noticioso comenzó a tener relevancia: el sexo ${ }^{124}$ y la excitación. ${ }^{125}$ Entonces, el segundo evento controversial tuvo lugar. El 12 de abril de 2017, en medio del juicio, el programa matinal Bienvenidos, Cada Uno Cuenta de C13 mostró, sin ediciones, el testimonio del perito que realizó el examen ginecológico. Esta declaración que había sido presentada el día anterior en el juicio por la defensa para desestimar el testimonio de la víctima. Este fue el único canal que transmitió esta declaración. Durante la transmisión, (en la zona inferior de la pantalla) se podía leer "Opiniones divididas en el caso de Nabila: médico no descartó agresión sexual” y luego “¿Hubo agresión sexual?". ${ }^{126}$ También, el reporte ginecológico reveló detalles de las características físicas de su cuerpo. La víctima describió esta transmisión en la demanda civil contra el canal como "indolente, ilegal y negligente". ${ }^{127}$ La exposición de este informe ginecológico representa un quiebre entre el público y los medios de comunicación. Inmediatamente después de que el programa matinal presentara el informe ginecológico, el público consideró que los medios habían excedido sus poderes para reportar los hechos. Debido a esta transmisión el Consejo Nacional de Televisión (en adelante, CNTV), organismo estatal que vela por el correcto funcionamiento de la televisión chilena, recibió 1.133 quejas del público, equivalente al $27 \%$ de todos los reclamos procesados por el Consejo durante el año 2017. ${ }^{128}$ Estos reclamos hacían referencia a la violación de derecho fundamentales y a la dignidad de las personas y, en particular, referidas al trato desigual entre hombres y mujeres y a la violación de la privacidad de las personas. ${ }^{129}$ Después de esta transmisión, este programa de televisión tuvo que dar disculpas públicas y parte de sus directores tuvieron que renunciar a su cargo. El mismo programa recibió una multa del CNTV y ahora enfrenta una demanda civil por daños morales. ${ }^{130}$

A pesar de esta respuesta adversa del público, el resto del juicio, que también revelaba aspectos de la vida íntima de la víctima, fue transmitido sin cuestionamiento por parte de los televidentes. Después del juicio, el Poder Judicial prohibió la transmisión de los testimonios de las víctimas, así como de los testimonios de peritos, testigos y del resto de la evidencia. ${ }^{131}$ Además, PJUDTV ahora sólo transmite los alegatos de apertura y de cierre de los abogados y el testimonio del acusado, si éste así lo solicita.

La pregunta que surge es cuáles aspectos de la declaración en vivo de la amiga del acusado y del informe ginecológico ya no fueron tolerables por el público al punto en que consideraron que los límites de la prensa fueron transgredidos en este asunto en particular. CNTV explica estos reclamos

\footnotetext{
123 PODER JUDICIAL TV (2017c), s/p.

124 JEWKES (2010), p. 56.

125 CHIBNALL (1997), passim.

${ }^{126}$ CANAL 13 (2017), passim.

${ }^{127}$ Demanda caratulada "Rifo con Canal 13 S.A. y otros" que fue presentada ante el $26^{\circ}$ Juzgado Civil de Santiago con fecha 23 de diciembre de 2017 y terminó por medio de una transacción extrajudicial seguida del desestimiento el 06 de junio de 2018, p. 3.

128 CONSEJO NACIONAL DE TELEVISIÓN (2017), passim.

${ }^{129}$ CONSEJO NACIONAL DE TELEVISIÓN (2017), p. 14-15.

${ }^{130}$ Demanda caratulada "Rifo con Canal 13 S.A. y otros" (2017).

131 EMOL (2017f), s/p.
} 


\section{Polít. Crim. Vol. 15, № 29 (Julio 2020), Art. 12, pp. 330-361 [http://politcrim.com/wp-content/uploads/2020/07/Vol15N29A12.pdf]}

diciendo que podrían deberse a "una mayor sensibilización frente a la Violencia Contra la Mujer (VCM) y que también es resultado de políticas públicas que buscan poner en la discusión temáticas sociales como esta". ${ }^{132}$ Sin embargo, es necesario entender esta respuesta del público dentro del contexto más amplio de los valores noticiosos. Como se señaló anteriormente, los investigadores de medios de comunicación señalan que el umbral o prominencia como uno de los valores periodísticos clave para considerar una historia como de interés noticioso. En un caso que se ha expuesto por un largo periodo de tiempo y en detalle, esta habilidad puede perderse y nuevos umbrales deben añadirse ya que, de acuerdo con Jewkes:

"un periodista pronto buscará un nuevo ángulo para mantener la historia "fresca" y para darle un factor novedoso. Esto puede simplemente involucrar una escalación en el nivel de drama ligado a la historia". ${ }^{133}$

A simple vista, este escalamiento parece no tener límites, puesto que los medios de comunicación buscan satisfacer "los deseos más voyeristas de las audiencias". ${ }^{134}$ Sin embargo, el rechazo generalizado a la revelación del testimonio del informe ginecológico da una clara señal de que la audiencia puede ser activa y que absorben el contenido de los medios de comunicación con cierta capacidad crítica.

La audiencia no solo recibe el juicio mediático, también puede poner a los medios de comunicación en juicio. Según Talbot, "los canales para quejarse respecto de la prensa y las transmisiones ofrecen otras oportunidades para una interacción tras bambalinas", ${ }_{135}$ esto se materializó en la entrevista a la amiga del acusado, la respuesta interactiva fue de apoyo hacia los medios de comunicación: fue una entrevista en vivo así que no era previsible lo que la entrevistada diría y, a pesar de eso, el canal de televisión apareció como protegiendo a la víctima. En el caso del informe ginecológico, la respuesta fue ampliamente negativa: el reporte fue expuesto al día siguiente de su presentación en el juicio, por lo tanto, se trató de una decisión editorial realizada conscientemente.

Después de la transmisión de la información ginecológica, este nivel de interactividad con el público causó que los reclamos al CNTV comenzarán a llegar inmediatamente puesto que pueden realizarse a través de internet. Al mismo tiempo, los reclamantes compartieron en línea el vínculo para invitar a otras personas en internet a que se unan a sus quejas. En esta etapa,

"la audiencia ya no es conceptualizada como quien internaliza pasivamente significados prefijados (...) sino que más bien se le otorga cierto grado de agencia en la interpretación y, así, "co-creando" los significados de las representaciones". ${ }^{136}$

Al final del juicio, el público estaba altamente involucrado. Debido a la exposición de los medios, cada persona tenía sus propias conclusiones basado en el juicio penal que fue transmitido, pero también basado en especulaciones que fueron presentadas por los medios de comunicación. Esto

${ }^{132}$ CONSEJO NACIONAL DE TELEVISIÓN (2017), p. 21.

133 JEWKES (2015), p. 50. Traducción por la autora de este artículo.

134 JEWKES (2015), p. 225. Traducción por la autora de este artículo.

135 TALBOT (2007), p. 156. Traducción por la autora de este artículo.

${ }^{136}$ YAR (2012), p. 248. Traducción por la autora de este artículo. 
significó que el caso dejara de ser una particularidad y comenzara a reflejar problemas sociales más complejos.

\subsection{Tercera Etapa - Post-juicio: Fracaso Institucional y Escándalo Institucional}

Después del juicio, los medios desviaron su atención de la víctima hacia otros aspectos del proceso. La víctima y su vida personal fueron explotadas al máximo durante el juicio y era el momento de cruzar un nuevo umbral, esta vez relacionado con el riesgo, la justicia y la necesidad de castigo. A pesar de que el proceso de sentencia no es usualmente mostrado por los medios de comunicación, ${ }^{137}$ en esta búsqueda de un nuevo umbral emergió un discurso crítico hacia el sistema, acusando un fracaso institucional. En esta área, la crítica del caso tuvo dos aristas aparentemente contradictorias: fracaso institucional por condenar a un inocente y fracaso institucional por no condenar adecuadamente al culpable. ${ }^{138}$ Esto significó que la sentencia fue atacada por los medios de dos formas distintas: en primer lugar, condenando la baja sentencia que se le dio al agresor; en segundo lugar, acusando una falta de prolijidad en la evidencia que lo condenó.

La primera noticia directamente relacionada con el fracaso de las instituciones se reveló el 9 de julio de 2017 cuando LT comenzó la "espiral de amplificación del escándalo"139 por medio de la filtración de los resultados del recurso interpuesto ante la Corte Suprema tres días antes de la fecha oficial de la sentencia. ${ }^{140}$ La Corte Suprema cambió la calificación jurídica de femicidio frustrado por el de lesiones graves en contexto de violencia intrafamiliar rebajando la condena de 26 a 18 años en prisión. Inmediatamente, otros medios de comunicación re-publicaron la información e, incluso, fueron a preguntarle a la víctima su opinión. ${ }^{141}$ Unos días después la Corte Suprema públicamente confirmó que habían reducido la sentencia y criticaron la filtración del fallo. ${ }^{142}$ Después de esto, se generaron protestas en las afueras de la Corte Suprema donde los grupos feministas y de apoyo a las víctimas con cárteles de "Justicia para Nabila" expresaron su descontento; como resultado, ocho personas fueron detenidas. ${ }^{143}$ También académicos y abogados comentaron negativamente la sentencia. ${ }^{144} \mathrm{El}$ programa matinal de CHV llamó a la víctima para que comentara la nueva sentencia y allí ella señaló que "en Chile no hay justicia". ${ }^{145} \mathrm{El}$ gobierno, a través de la ministra de la Mujer y la Equidad de Género señaló "lo respetamos, pero no nos deja conforme". ${ }^{146}$

La mayor parte de las críticas provenían del cambio de femicidio frustrado al delito de lesiones. El femicidio como delito en Chile sólo ha existido desde el año 2010 y se refiere al homicidio

\footnotetext{
${ }^{137}$ ROBINSON (2011), passim.

138 GREER y MCLAUGHLIN (2017b), passim.

${ }^{139}$ GREER y MCLAUGHLIN (2012b), passim.

${ }^{140}$ LA TERCERA (2017b), passim.

${ }^{141}$ LA CUARTA (2017b), passim.

142 PODER JUDICIAL TV (2017c), s/p.

143 TELE 13 (2017), s/p.

${ }^{144}$ LA TERCERA (2017a), passim. LAS ÚLTIMAS NOTICIAS (2017), passim.

145 CHILEVISION (2017), s/p..

${ }^{146}$ EMOL (2017c), passim.
} 


\section{Polít. Crim. Vol. 15, № 29 (Julio 2020), Art. 12, pp. 330-361 [http://politcrim.com/wp-content/uploads/2020/07/Vol15N29A12.pdf]}

cometido contra la esposa, la pareja mujer, exesposa o expareja mujer. ${ }^{147}$ La misma ley requiere que el Ministerio de la Mujer y la Equidad de Género mantenga una lista pública de los femicidios cometidos en el país. ${ }^{148}$ Desde entonces, la lucha contra el femicidio ha sido uno de los pilares fundamentales de los movimientos feministas y de igualdad de género en su ataque contra el machismo. El cambio de la Corte Suprema de femicidio a lesiones fue considerado como una pérdida en la lucha contra la violencia de género y los medios de comunicación alentaron esta insatisfacción mostrando el sentimiento de injusticia que la víctima sintió. ${ }^{149}$

Este repudio general y global ${ }^{150}$ de la nueva sentencia fue una crítica directa al Poder Judicial. Dado esto, el Poder Judicial no pudo mantenerse al margen y tuvo que hacer un video explicativo $^{151}$ y compartieron una infografía en las páginas oficiales de sus redes sociales para explicar la decisión al público. ${ }^{152}$ No es común que el Poder Judicial justifique tan explícitamente sus acciones ante la comunidad a través de redes sociales. Este parece ser otro efecto del juicio mediático y de la audiencia activa que se ha desarrollado debido a la alta exposición del juicio. Estas representaciones mediáticas,

“(se) han fusionado para crear una esfera mediática altamente adversarial, volátil e interactiva en la cual las autoridades y élites deben crecientemente luchar en contra del flujo de la opinión de los medios de comunicación para mantener un perfil público positivo". ${ }^{153}$

Sin embargo, esta no fue la única crítica que las instituciones recibieron. Dos meses después de estos incidentes, una investigación periodística fue presentada en el programa de televisión Informe Especial. Este programa ha aparecido por más de 30 años en la televisión chilena y tiene una tradición de rigor periodístico y ahora es parte del noticiero 24 Horas de TVN. ${ }^{154}$ En este caso, hicieron un reportaje llamado "Las Dudas en el Caso de Nabila Rifo" 155 donde abiertamente cuestionaron la evidencia presentada por la Fiscalía y, por lo tanto, el resultado del juicio donde Mauricio Ortega fue encontrado culpable. El programa concluye diciendo:

"En este momento hay decenas de víctimas como Nabila e imputados como Mauricio esperando que se haga justicia. A modo de ejemplo, Informe Especial hoy puso una luz de alerta sobre los estándares con los que policías, peritos, defensores y fiscales trabajaron en esta oportunidad; del rigor profesional de cada uno de ellos depende la aplicación de justicia. Presos injustos o delincuentes en libertad es lo que se puede evitar". ${ }^{156}$

En este caso, las críticas se extienden más allá de los jueces y cubre a todos los relacionados al sistema de justicia criminal. La falta de legitimidad de los diferentes elementos del sistema, en este

\footnotetext{
${ }^{147}$ Esta es la ley 20.480 del año 2010 que "Modifica el Código Penal y la Ley No 20.066 Sobre Violencia Intrafamiliar, Estableciendo el "Femicidio", Aumentando las Penas Aplicables a este Delito y Reforma Las Normas Sobre Parricidio".

148 MINISTERIO DE LA MUJER Y LA EQUIDAD DE GÉNERO (2018), passim.

${ }^{149}$ LA CUARTA (2017a), passim.

${ }^{150}$ BBC UK NEWS (2017), s/p.

${ }^{151}$ PODER JUDICIAL TV (2017e), s/p.

152 PODER JUDICIAL (2017a), s/p; PODER JUDICIAL (2017b), s/p.

153 GREER y MCLAUGHLIN (2011), p. 28. Traducción por la autora de este artículo.

15424 HORAS (2017), s/p.

15524 HORAS (2017), s/p.

15624 HORAS (2017), minuto 31:45.
} 


\section{MARDONES, Daniela: "Representación mediática y cobertura de los medios de las mujeres víctimas de violencia intrafamiliar en Chile: El caso de Nabila Rifo".}

caso, alcanza los niveles de "escándalo institucional", ${ }^{157}$ al contribuir a la disminución de la confianza pública en la justicia chilena. El programa Informe Especial declara que no es su intención decir que Mauricio Ortega es inocente, sino que el trabajo de investigadores y fiscales es deficiente. Por lo tanto, su principal objetivo es mostrar el fracaso institucional al condenar a Mauricio Ortega. Inmediatamente después del reportaje, los comentarios públicos comenzaron a apoyar las dudas destacando que la investigación de Fiscalía estuvo contaminada por la presión de los grupos feministas, el gobierno y la Ministra de la Mujer y que el acusado había sido condenado por los medios aun antes del juicio. ${ }^{158}$ Esta reacción es completamente opuesta a la que ocurrió dos meses antes debido a la reducción de la sentencia donde el público criticó a los jueces diciendo que eran unos hipócritas, sexistas, y algunos comentarios incluso solicitaban el regreso de la pena de muerte. ${ }^{159}$

Estos dos eventos noticiosos nos muestran como el escalamiento del escándalo se produce de manera contradictoria. En palabras de Thompson "los escándalos son a menudo asuntos bastante desordenados relacionados con la supuesta transgresión de valores y normas que están en sí mismos sujeto a contestación". ${ }^{160}$ En esta etapa, las consecuencias de la pérdida de credibilidad de la víctima durante la investigación todavía pueden apreciarse en el rechazo de ciertas personas a apoyar la condena de Mauricio Ortega.

Sin embargo, más allá de enfocarse en la credibilidad de la víctima, el foco estuvo en el sistema de justicia criminal. Greer y McLaughlin sugieren que:

"la preocupación de la prensa por el escándalo y el fracaso, y el surgimiento de la política de indignación en la prensa está minando la confianza no solo en la clase política como individuos (...) sino también en instituciones enteras". ${ }^{161}$

Es decir, más que apuntar a los jueces la crítica fue a la Corte Suprema como un todo. Tampoco fue la intención atacar al fiscal del caso, sino que a todo el sistema de persecución criminal.

En esta etapa, la representación mediática de la víctima adquirió otra característica porque, sumado a su brutal ataque, ella también fue víctima de la injustica del sistema. A su vez, una parte de la opinión pública comenzó a considerar al atacante como víctima del fracaso institucional. Por lo tanto, es presentado como si no hubiera un lado ganador, como si todos los involucrados fueron perjudicados por este fracaso institucional. Entonces, después del escándalo y la subsecuente amplificación espiral, el "veredicto de los medios" es "injusticia institucionalizada". ${ }^{162}$ En esta última etapa, los medios de comunicación escalaron el caso a todo el sistema de justicia criminal.

\section{Conclusión}

En este artículo, he argumentado que la cobertura mediática del caso de Nabila Rifo por la prensa chilena cambió a lo largo de los más de dos años en que se presentó en los medios, con el fin de

${ }^{157}$ GREER y MCLAUGHLIN (2017b), passim.

${ }^{158}$ EMOL (2017b), passim.

${ }^{159}$ EMOL (2017b), passim.

${ }^{160}$ THOMPSON (1997), p. 41. Traducción por la autora de este artículo.

${ }^{161}$ GREER y MCLAUGHLIN, p. 289. Traducción por la autora de este artículo.

${ }^{162}$ GREER y MCLAUGHLIN, p. 290. Traducción por la autora de este artículo. 


\section{Polít. Crim. Vol. 15, № 29 (Julio 2020), Art. 12, pp. 330-361 [http://politcrim.com/wp-content/uploads/2020/07/Vol15N29A12.pdf]}

mantener su valor noticioso. Esta noción de variabilidad es central en esta investigación. La representación mediática de la víctima y el foco de la atención de los medios escaló desde la personalización de la víctima hasta una aproximación de fracaso institucional general.

El objetivo de esta investigación era aplicar un marco de referencia teórico criminológico al investigar las diferentes etapas de la cobertura mediática de víctimas en Chile. El método de estudio de caso probó ser útil para profundizar y ejemplificar las estructuras subyacentes en la construcción de la representación de víctimas en el contexto chileno. Este caso único representa el escenario perfecto para aplicar un contexto teórico más amplio y alcanzar el reto de describir y comprender la representación de noticias y la construcción social en el retrato de las víctimas con un enfoque novedoso desde la criminología para la investigación chilena.

En esta investigación se encontró que, en cada etapa, los medios de comunicación se enfocaron de manera diferente, cambiando la representación mediática de la víctima, los valores noticiosos y la respuesta del público. A pesar de que no es posible generalizar los resultados debido a las limitaciones del estudio de un único caso, aun así, es posible comparar los distintos estados de este para entender la lógica del valor noticioso que se encuentra detrás de las decisiones de la prensa chilena en este caso.

En primer lugar, la representación mediática y el retrato de la víctima fue fluctuante desde la víctima ideal hacia una que puede ser culpada por lo que le pasó. En este sentido, los medios de comunicación chilenos no difieren mucho de las representaciones usuales descritas en las teorías generales sobre víctimas. Inicialmente, la historia se enfocaba en su estatus de mujer de ciudad pequeña, pero su cercanía con el atacante y las contradicciones en su relato rápidamente la hicieron perder sus características de víctima ideal. Durante este proceso, ella dejó de tener su propia individualidad y se volvió representante de una categoría de víctimas apoyada por grupos feministas y el gobierno que quería promover su agenda de género. Es posible ver aquí los valores noticiosos del umbral y de la personalización, pero esta personalización también estuvo relacionada a culparla en la medida que la opinión pública cambió desde el apoyo incondicional a la víctima a un intenso escrutinio de su vida personal y privada.

En segundo lugar, la larga exposición generada por la transmisión televisada del juicio causó que los medios de comunicación llevaran a cabo un juicio paralelo, sacando sus propias conclusiones, usualmente apresuradas y sin tener o contemplar todos los aspectos del caso. Esto puede ser explicado por el concepto general de "juicio mediático". Sin embargo, este juicio mediático aumentó en intensidad hasta el punto en que la vida sexual de la víctima ganó relevancia. En estas circunstancias, la exposición del reporte ginecológico se transforma en el hito que marca el distanciamiento del público con los medios. La respuesta del público fue intensamente negativa hacia el programa que presentó el informe. Sin embargo, la respuesta del público también puede ser positiva y de apoyo a decisiones editoriales inesperadas como cuando se terminó abruptamente la entrevista a quien culpó abiertamente a la víctima. Estos hechos representan la existencia de audiencia activas que van más allá de simples observadores formando una parte relevante del juicio mediático.

Finalmente, el proceso que fue desarrollado al final refleja el interés de generar un nuevo umbral noticioso. Esto fue llevado a cabo al empezar la amplificación de la espiral del escándalo al filtrar 
la sentencia de la Corte Suprema y al acusar un fracaso institucional dentro del sistema de justicia criminal a través de un programa de televisión. Todos estos procesos de construcción del escándalo institucional llevan a la representación de un sentimiento de injusticia generalizada. Por consiguiente, nadie está satisfecho con las conclusiones que los medios de comunicación sacaron del caso: los que apoyan a la víctima creen que la condena fue muy baja y los que apoyan al agresor creen que el procedimiento fue defectuoso.

En resumen, el proceso de construcción de noticias en este caso puede ser efectivamente explicado a través de los conceptos criminológicos de valor noticioso, interés periodístico, víctima ideal, juicio mediático, escándalo y fracaso institucional.

Estos resultados tienen implicaciones relevantes para entender cómo y por qué Nabila Rifo fue retratada como víctima por los medios de comunicación chilenos. También, esto reconoce el vínculo que existe entre las teorías generales sobre medios de comunicación y crímenes que pueden ser aplicadas en un extenso caso en el contexto chileno. Esto es porque, como se señaló al principio, el contexto mediático chileno está basado en medios privados. A la fecha de estos acontecimientos, todos los periódicos y canales de televisión desde los cuales se extrajeron las noticias dependían de la publicidad y de los ratings de audiencia para mantenerse, incluso TVN. ${ }^{163}$ Por lo tanto, están relacionados a los mismos problemas presentados por la prensa en otros países que dependen fuertemente del libre mercado, como Estados Unidos o el Reino Unido, que son las principales fuentes de las teorías aquí utilizadas.

En consecuencia, esta investigación se constituye como un estudio preliminar donde diferentes teorías criminológicas y sobre medios de comunicación fueron utilizadas para explicar el comportamiento de los medios chilenos en las diferentes situaciones de un caso extenso. Sin embargo, se requiere de mayores estudios en profundidad para aplicar estas teorías ajustándolas con mayor precisión a la realidad latinoamericana relacionada con la violencia de género y la cultura machista. Es necesario realizar más investigaciones para generalizar los procesos de construcción de noticias aquí descritos incluyendo también una perspectiva de género y comparada con otros casos de relevancia mediática en Chile como el caso de Karina Sepúlveda o los recientes casos del profesor Nibaldo Villegas y de Fernanda Maciel.

A pesar de estas limitaciones, esta investigación es una contribución valiosa considerando la escasez de estudios criminológicos en Chile y que la relación entre los estudios de medios y la criminología es un campo no muy explorado dentro de la investigación académica en Chile a pesar de que una gran cantidad de las noticias presentadas en los medios de comunicación se refieren a crímenes.

\footnotetext{
${ }^{163}$ Hasta el año 2018, TVN dependía completamente de la inversión y publicidad de privados para funcionar. Desde la reforma legal puede recibir dinero del presupuesto del Estado y, a la vez, se ha querido potenciar su labor pública como canal estatal.
} 


\section{Bibliografía}

BENEDICT, Helen (1992): Virgin or vamp: how the press covers sex crimes (Oxford: Oxford University Press).

BIENECK, Stefen; KRAHÉ, Bárbara (2011): "Blaming the Victim and Exonerating the Perpetrator in Cases of Rape and Robbery: Is There a Double Standard?”, en: Journal of Interpersonal Violence (vol. 26, no. 9) pp. 1785-1797. Disponible en: https://doi.org/10.1177/0886260510372945 [Visitado el 01.07.2018].

BIGNELL, Jonathan (2002): Media semiotics: an introduction, 2 (Manchester: Manchester University Press).

CHIBNALL, Steve (1997): Law-and-order news: an analysis of crime reporting in the British press (London: Tavistock Publications).

CHRISTIE, Nils (1986): “The Ideal Victim”, en: FATTAH, Ezzat (ed.), From Crime Policy to Victim Policy. (London: Palgrave Macmillan UK), pp. 17-30. Disponible en: http://link.springer.com/10.1007/978-1-349-08305-3_2 [Visitado el 20.07.2018].

CLAY, Eliana (2011): Campaigning Against Violence Against Women From the Women's and Feminist Movement: A Case Study of the ¡Cuidado! El Machismo Mata Campaign in Chile. Halifax: Saint Mary's University. Disponible en: http://library2.smu.ca/handle/01/23746\#.XREQuohKi00 [Visitado el 02.07.2018].

COHEN, Stanley (2017): Demonios populares y pánicos morales: delincuencia juvenil, subculturas, vandalismo, drogas y violencia (Trad.: María de los Ángeles Boschiroli, Barcelona: Gedisa).

CONSEJO NACIONAL DE TELEVISIÓN (2015): Concentracion De Medios Televisivos (Santiago: Consejo Nacional de Televisión). Disponible en: https://www.cntv.cl/cntv/site/artic/20161129/asocfile/20161129122746/concentracion_de _medios_televisivos.ppt [Visitado el 15.06.2018].

CONSEJO NACIONAL DE TELEVISIÓN (2017): Balance de denuncias ciudadanas 2017 (Santiago: Consejo Nacional de Televisión). Disponible en: https://www.cntv.cl/cntv/site/artic/20180322/asocfile/20180322115514/balance_denuncia s_ciudadanas_2017_final.pdf [Visitado el 29.06.2018].

DE WAARDT, Mijke (2016): "Naming and Shaming Victims: The Semantics of Victimhood" en: International Journal of Transitional Justice (vol. 10, no. 3), pp. 432-450. Disponible en: https://doi.org/10.1093/ijtj/ijw011 [Visitado el 01.07.2018].

DUCE, Mauricio; MORENO, Leonardo; ORTIZ DE URBINA GIMENO, Íñigo; MALDONADO, Francisco; CARNEVALI, Raúl; MATUS, Jean Pierre; JIMénez, María Angélica; NEIRA, Marcela; SALINERO, Sebastián; RAMÍREZ, Cecilia (2014): "La víctima en el sistema de justicia penal: Una perspectiva jurídica y criminológica", en: Polít. crim. (vol.9, n.18), pp.739-815. Disponible en: http://dx.doi.org/10.4067/S0718-33992014000200014 [Visitado el 21.09.2018].

ELIAS, Robert (1993): Victims still: the political manipulation of crime victims (London: SAGE). FINE, Gary (1997): "Scandal, Social Conditions, and the Creation of Public Attention: Fatty Arbuckle and the "Problem of Hollywood", en: Social Problems (vol. 44, no. 3) pp. 297323. Disponible en: https://academic.oup.com/socpro/article-lookup/doi/10.2307/3097179 [Visitado el 19.12.2017]. 
GALTUN, Johan; RUGE, Mari (1973): “Structuring and Selecting News", en: YOUNG, Jock y COHEN, Stanley (eds.), The manufacture of news: social problems, deviance and the mass media (London: Constable), pp. 62-73.

GARLAND, David (2001): The culture of control: crime and social order in contemporary society (Chicago: University of Chicago Press).

GOBIERNO DE CHILE, "Coyhaique”, [sin fecha], en: http:/www.subdere.cl/divisiónadministrativa-de-chile/gobierno-regional-de-aisén/provincia-de-coyhaique/coyhaique [Visitado el 11.08.2018].

GOMM, Roger; HAMMERSLEY, Martyn; FOSTER, Peter (2000): Case study method: key issues, key texts (London: SAGE).

GOVIER, Trudy (2015): Victims and victimhood (Ontario: Broadview Press).

GRACIA, Enrique (2014): "Intimate partner violence against women and victim-blaming attitudes among Europeans", en: Bulletin of the World Health Organization (vol. 92), pp. 380-381. Disponible en: http://www.who.int/entity/bulletin/volumes/92/5/13-131391.pdf [Visitado el 17.07.2018].

GREER, Chris y MCLAUGHLIN, Eugene (2011): “Trial by media': Policing, the 24-7 news mediasphere and the "politics of outrage", en: Theoretical Criminology (vol. 15, no. 1), pp. 23-46. Disponible en: http://journals.sagepub.com/doi/10.1177/1362480610387461 [Visitado el 17.07.2018].

GREER, Chris y MCLAUGHLIN, Eugene (2012a): "Media justice: Madeleine McCann, intermediatization and 'trial by media' in the British press", en: Theoretical Criminology (vol. 16, no. 4), pp. 395-416. Disponible en: http://journals.sagepub.com/doi/10.1177/1362480612454559 [Visitado el 07.08.2018].

GREER, Chris y MCLAUGHLIN, Eugene (2012b): "THIS IS NOT JUSTICE": Ian Tomlinson, Institutional Failure and the Press Politics of Outrage", en: The British Journal of Criminology (vol. 52, no. 2), pp. 274-293. Disponible en: http://www.jstor.org/stable/44173489 [Visitado el 17.07.2018].

GREER, Chris y MCLAUGHLIN, Eugene (2017a): "News Power, Crime and Media Justice", en: LIEBLING, Alison; MCARA, Lesley y MARUNA, Shadd (eds.), The Oxford Handbook of Criminology, 6 (Oxford: Oxford University Press), pp. 260-283. Disponible en: http://openaccess.city.ac.uk/17016/ [Visitado el 16.07.2018].

GREER, Chris y MCLAUGHLIN, Eugene (2017b): "Theorizing institutional scandal and the regulatory state", en: Theoretical Criminology (vol. 21, no. 2), pp. 112-132. Disponible en: https://doi.org/10.1177/1362480616645648 [Visitado el 29.05.2018].

HALL, Matthew (2017): Victims of Crime. Construction, Governance and Policy 1, (S.I): Springer International Publishing. Disponible en: https://link.springer.com/book/10.1007\%2F9783-319-64589-6 [Visitado el 01.07.2018].

HALL, Stuart; Chas CRITCHER, JEFFERSON, Tony; CLARKE, John; ROBERTS, Brian (1978): Policing the Crisis: Mugging, the State, and Law and Order, 1, (London: The Macmillan Press Ltd).

HARTLEY, John (1982): Understanding news (London: Methuen).

JEWKES, Yvonne (2010): “The Construction of Crime News (2004)”, en: GREER, Chris (ed.), Crime and the Media: A reader, 1 (New York: Routledge), pp. 215-227.

JEWKES, Yvonne (2015): Media \& crime, 3 (London: SAGE). 
KATZ, Jack (1987): “What makes crime 'news'?”, en: Media, Culture \& Society (vol. 9, no. 1), pp. 47-75. Disponible en: http://journals.sagepub.com/doi/10.1177/016344387009001004 [Visitado el 03.07.2018].

LANZA, Edinson (2017): Situación de la Libertad de Expresión en Chile. Informe Especial de país 2016, (S.I): Comision Interamericana de Derechos Humanos OEA. Disponible en: http://www.oas.org/es/cidh/expresion/docs/publicaciones/INFORME_PAIS_Chile.pdf [Visitado el 08.08.2018].

LATHROP, Fabiola (2013): "El Derecho a la Imagen de Niños, Niñas y Adolescentes en Chile. Una mirada crítica a la luz del Derecho Internacional de los Derechos Humanos y de los Estatutos Normativos Iberoamericnanos de Protección Integral de la Infancia y Adolescencia”, en: Revista Chilena de Derecho (vol. 40, no. 3), pp. 929-952. Disponible en: https://www.jstor.org/stable/23729644 [Visitado el 15.07.2018].

LATIN AMERICAN AND CARIBBEAN WOMEN'S HEALTH NETWORK (2008): “Careful! Machismo kills", en: Women's Health Journal (vol. 1), pp. 46-49. Disponible en: http://go.galegroup.com.ezproxy.is.ed.ac.uk/ps/i.do?id=GALE\%7CA198415397\&v=2.1 $\& u=e d \_$itw\&it=r\&p=AONE\&sw=w [Visitado el 02.07.2018].

MARSH, Ian; MELVILLE, Gaynor (2009): Crime, justice and the media (London: Routledge). Disponible en: https://www.routledge.com/Crime-Justice-and-the-Media/MarshMelville/p/book/9780203894781 [Visitado el 01.06.2018].

MEYERS, Marian (1994): "News of Battering", Journal of Communication (vol. 44, no. 2), pp. 47-63, en: https://academic.oup.com/joc/article/44/2/47-63/4160019 [Visitado el 18.07.2018].

MEYERS, Marian (1997): News coverage of violence against women: engendering blame, (London: Sage Publications).

MINISTERIO DE LA MUJER Y LA EQUIDAD DE GÉNERO (2018): "Femicidios", en: https://www.minmujeryeg.cl/sernameg/programas/violencia-contra-lasmujeres/femicidios/ [Visitado el 09.08.2018].

NAYLOR, Bronwyn (1995): “Women's Crime and Media Coverage: Making explanations", en: DOBASH, Rebecca; DOBASH, Russell y NOAKS, Lesley (eds.), Gender and Crime, (Cardiff: University of Wales Press), pp. 77-95.

REINER, Robert; LIVINGSTONE, Sonia; ALLEN, Jessica (2001): "Casino culture: media and crime in a winner-loser society", en: STENSON, Kevin; SULLIVAN, Robert (eds.), Crime, Risk and Justice: the politics of crime control in liberal democracies (Cullompton, Devon: Willan Publishing), pp. 174-194. Disponible en: https://core.ac.uk/download/pdf/94114.pdf [Visitado el 15.07.2018].

ROBINSON, Matthew (2011): Media coverage of crime and criminal justice (Durham: Carolina Academic Press).

ROCK, Paul (1990): Helping victims of crime: the Home Office and the rise of victim support in England and Wales (Oxford: Clarendon Press).

TALBOT, Mary (2007): Media discourse: representation and interaction (Edinburgh: Edinburgh University Press).

THOMPSON, John (1997): "Scandal and Social Theory", en: LULL, James y HINERMAN, Stephen (eds.), Media scandals: morality and desire in the popular culture marketplace (Oxford: Polity), pp. 34-64.

US DEPARTMENT OF STATE - FREEDOM OF INFORMATION ACT., "El Mercurio Report",

(S.I:

S.I),

1973,

en: 
MARDONES, Daniela: “Representación mediática y cobertura de los medios de las mujeres víctimas de violencia intrafamiliar en Chile: El caso de Nabila Rifo".

https://foia.state.gov/searchapp/DOCUMENTS/PCIA3/000099ED.pdf [Visitado el 12.07.2018].

VALIDA (2017) Boletin de circulación y lectura $1^{\circ}$ Semestre 2017 (Santiago: Deloitte Ipsos). Disponible en: http://www.valida-chile.cl/wp-content/uploads/2017/02/Boleti\%CC\%81nde-Circulacio\%CC\%81n-y-Lectura-Diarios-y-revistas-1\%C2\%BA-Semestre-2017-.pdf [Visitado el 09.07.2018].

VAN DIJK, Jan (2009): “Free The Victim: A Critique of The Western Conception of Victimhood", en: International Review of Victimology (vol. 16), pp. 1-33. Disponible en: http://journals.sagepub.com/doi/pdf/10.1177/026975800901600101 [Visitado el 28.06.2018].

VICTIM WITNESS ASSISTANCE UNIT (2008): Understanding Domestic Violence: A Handbook for Victims and Professionals (Washington, DC: US Government Printing Office).

YAR, Majid (2012): "Crime, media and the will-to- representation: Reconsidering relationships in the new media age", en: Crime Media Culture (vol. 8, no. 3), pp. 245-260, en: http://journals.sagepub.com/doi/pdf/10.1177/1741659012443227 [Visitado el 26.12.2017].

YIN, Robert (2009): Case study research : design and methods, 4 (Thousand Oaks: SAGE).

\section{Prensa}

24 HORAS (2016a): "Este es el audio con el que Nabila Rifo defendería a su pareja y acusa presiones de fiscal - Nacional", 23.08.2016. Disponible en:http://www.24horas.cl/nacional/este-es-el-audio-con-el-que-nabila-rifo-defenderia-asu-pareja-y-acusa-presiones-de-fiscal-2111643 [Visitado el 16.06.2018].

24 HORAS (2016b): "Familia de mujer atacada en Coyhaique asegura que sufría violencia intrafamiliar - $\quad$ Nacional", 15.05.2016. Disponible en: http://www.24horas.cl/nacional/familia-de-mujer-atacada-en-coyhaique-asegura-quesufria-violencia-intrafamiliar-2015902 [Visitado el 12.06.2018].

24 HORAS (2016c): "Masiva manifestación por brutal ataque a mujer en Coyhaique - Nacional", 14.05.2016. Disponible en: http://www.24horas.cl/nacional/masiva-manifestacion-porbrutal-ataque-a-mujer-en-coyhaique-2015415 [Visitado el 16.06.2018].

24 HORAS (2016d): "Mujer brutalmente atacada en Coyhaique sale de riesgo vital - Nacional", 16.05.2016. Disponible en: http://www.24horas.cl/nacional/mujer-brutalmente-atacadaen-coyhaique-sale-de-riesgo-vital-2016910 [Visitado el 13.06.2018].

24 HORAS (2016e): "Presidenta Bachelet tras visita a Nabila Rifo: "Vamos a trabajar para que estos casos no vuelvan a suceder" - Nacional", 18.05.2016. Disponible en: http://www.24horas.cl/nacional/presidenta-bachelet-tras-visita-a-nabila-rifo-vamos-atrabajar-para-que-estos-casos-no-vuelvan-a-suceder-2018564 [Visitado el 16.06.2018].

24 HORAS (2017): "Informe Especial: "Las dudas en el caso de Nabila Rifo"- Informe Especial", 10.09.2017. Disponible en: http://www.24horas.cl/programas/informeespecial/informeespecial-las-dudas-en-el-caso-de-nabila-rifo-2501440 [Visitado el 15.06.2018].

24 HORAS (s/f): "Informe Especial". Disponible http://www.24horas.cl/programas/informeespecial/. [Visitado el 16.08.2018].

BBC UK NEWS (2017): "Nabila Rifo: Chile court cuts jail term of attacker". Disponible en: https://www.bbc.co.uk/news/world-latin-america-40580037 [Visitado el 11.07.2018]. 
BETHIA, Bethia (s/f): Sitio Corporativo. Disponible en: http://www.bethia.cl/\#empresas-quegestionamos [Visitado el 12.07.2018].

CANAL 13 (2017): "Caso Nabila: Las opiniones son divididas | Bienvenidos", YouTube Online Video, 12.04.2017. Disponible en: https://www.youtube.com/watch?v=8DupbgiaIqM [Visitado el 2 .07.2018].

CANAL 13 (s/f): Canal 13 Sitio Corporativo. [sin fechaa]. Disponible en: http://www.13.cl/ [Visitado el 1806 2018].

CANAL 13 (s/f): YouTube Channel. Disponible en: https://www.youtube.com/user/canal13 [Visitado el 11.06.2018].

CHILEVISION (2016a): "Mujer terminó sin ojos tras brutal agresión en Coyhaique - La Mañana", YouTube Online Video, 16.05.2016. Disponible en: https://www.youtube.com/watch?v=LodiaN9VVgo [Visitado el 13.06.2018].

CHILEVISION (2017): "Nabila Rifo se refirió a rebaja de condena a Mauricio Ortega - La Mañana" YouTube Online Video, 12.07.2017. Disponible en: https://www.youtube.com/watch?v=NXYQjiNRrsg. [Visitado el 1706 2018].

CHILEVISION (s/f): YouTube Channel. Disponible en: https://www.youtube.com/user/chvtevedeverdad [Visitado el 11 .06. 2018].

CHILEVISION (s/f): Chilevision Sitio Corporativo. Disponible en: http://www.chilevision.cl/ [Visitado el 29.06.2018].

EMOL (2017a): ““Bienvenidos” se disculpa por emitir contenido de informe ginecológico de Nabila Rifo: "Fue un error humano"", 13.04.2017. Disponible en: http://www.emol.com/noticias/Espectaculos/2017/04/13/854048/Equipo-de-Bienvenidospide-disculpas-por-emitir-contenido-de-informe-ginecologico-de-Nabila-Rifo.html.

[Visitado el 04.07.2018].

EMOL (2017b): "Caso Nabila Rifo: Mauricio Ortega insiste en su inocencia en reportaje que planteó dudas sobre pruebas de la investigación" 10.09.2017. Disponible en: http://www.emol.com/noticias/Nacional/2017/09/10/874798/Caso-Nabila-Rifo-MauricioOrtega-insiste-en-su-inocencia-en-reportaje-que-planteo-dudas-sobre-pruebas-de-lainvestigacion.html. [Visitado el 10.07.2018].

EMOL (2017c): "Gobierno y fallo de la Corte Suprema por caso Nabila Rifo: Lo respetamos, pero no nos deja conformes", 11.07.2017. Disponible en: http://www.emol.com/noticias/Nacional/2017/07/11/866426/Gobierno-y-fallo-de-laCorte-Suprema-por-caso-Nabila-Rifo-Lo-respetamos-pero-no-nos-deja-conformes.html [Visitado el 17.06.2018].

EMOL (2017d): "Justicia para Nabila: El caso en que se involucró Bachelet y le dio un nuevo impulso a su agenda de género", 18.04.2017. Disponible en: http://www.emol.com/noticiaf/Nacional/2017/04/18/854589/Justicia-para-Nabila-El-

caso-en-que-se-involucro-Bachelet-y-le-dio-un-nuevo-impulso-a-su-agenda-degenero.html [Visitado el 16.06.2018].

EMOL (2017e): "Masivo rechazo genera eventual rebaja de condena al agresor de Nabila Rifo", 07.09.2017.

http://www.emol.com/noticias/Nacional/2017/07/09/866124/Masivo-rechazo-generaeventual-rebajar-de-condena-al-agresor-de-Nabila-Rifo.html. [Visitado el 10.07.2018].

EMOL (2017f): "Poder Judicial no transmitirá más en su canal testimonios de víctimas tras caso de Nabila Rifo", 23.04.2017, en: http://www.emol.com/noticias/Nacional/2017/04/23/855305/Poder-Judicial-no- 
transmitira-mas-en-su-canal-testimonios-de-victimas-tras-caso-de-Nabila-Rifo.html. [Visitado el 11.08.2018].

EMOL (2016a): "Las contradicciones y múltiples versiones que han marcado la investigación por la brutal golpiza a Nabila Rifo", 09.09.2016. Disponible en: http://www.emol.com/noticias/Nacional/2016/09/09/821314/Las-contradicciones-ymultiples-versiones-que-han-marcado-la-investigacion-por-la-brutal-golpiza-a-NabilaRifo.html [Visitado el 16.06.2018].

EMOL (2016b): "Nabila Rifo acusa presiones de la Fiscalía y exculpa a principal imputado de brutal agresión", 22.08.2016. Disponible en: http://www.emol.com/noticias/Nacional/2016/08/22/818464/Nabila-Rifo-acusapresiones-de-la-Fiscalia-y-exculpa-a-principal-imputado-de-brutal-agresion.html [Visitado el 16.06.2018].

FORBES (s/f): “Alvaro Saieh Bendeck”. Disponible en: https://www.forbes.com/profile/alvarosaieh-bendeck/\#7a93ee455537 [Visitado el 11.07.2018].

INDEPENDENT (2017): "Man who beat girlfriend unconscious, gouged out her eyes then left her to die has sentence reduced", 12.07.2017. Disponible en: https://www.independent.co.uk/news/world/americas/domestic-violence-chile-nabilorifo-girlfriend-unconcious-gouge-eyes-mauricio-ortega-sentence-a 7837661.html. [Visitado el 11.07.2018].

LA CUARTA (2016a): "Detalles del salvaje ataque a mujer en Coyhaique", 15.05.2016. Disponible en: http://www.lacuarta.com/noticia/detalles-del-salvaje-ataque-a-mujer-encoyhaique/ [Visitado el 16.06.2018].

LA CUARTA (2016b): "Ex pareja de Nabila Rifo desde la cárcel: “¿A quiénes están encubriendo?" 06.09.2016. Disponible en: https://www.lacuarta.com/cronica/noticia/expareja-de-nabila-rifo-desde-la-carcel-a-quienes-estan-encubriendo/172066/ [Visitado el 11.07.2018].

LA CUARTA (2016c): "Los coletazos tras vuelco en caso de Nabila Rifo", 24.08.2016. Disponible en: http://www.lacuarta.com/noticia/los-coletazos-tras-vuelco-en-caso-denabila-rifo/. [Visitado el 04.07.2018].

LA CUARTA (2017a): “La sentida reaccion de Nabila por el fallo a favor de Ortega: “Acá en Chile no hay justicia"”, 07.12.2017. Disponible en: https://www.lacuarta.com/cronica/noticia/reaccion-nabila-fallo/218745/ [Visitado el 11.08.2018].

LA CUARTA (2017b): "Nabila Rifo y decisión de la Corte: "Sé que no le rebajarán los años"”, 10.07.2017. Disponible en: https://www.lacuarta.com/cronica/noticia/nabila-rifo-se-queno-le-rebajaran-los-anos/218416/ [Visitado el 10.07.2018].

LA TERCERA (2016a): "Caso de Nabila Rifo marcó anuncio sobre cambios a la Ley de Violencia Intrafamiliar", 21.05.2016. Disponible en: http://www2.latercera.com/noticia/caso-denabila-rifo-marco-anuncio-sobre-cambios-a-la-ley-de-violencia-intrafamiliar/ [Visitado el 16.06.2018].

LA TERCERA (2017a): “Caso Nabila: penalistas descartan cambios a la ley y apuntan a criterio de la Suprema", 13.07.2017. Disponible en: http://www2.latercera.com/noticia/casonabila-penalistas-descartan-cambios-la-ley-apuntan-criterio-la-suprema/ [Visitado el 10.07.2018]. 


\section{Polít. Crim. Vol. 15, № 29 (Julio 2020), Art. 12, pp. 330-361 [http://politcrim.com/wp-content/uploads/2020/07/Vol15N29A12.pdf]}

LA TERCERA (2017b): "Corte Suprema acuerda rebajar la condena al agresor de Nabila Rifo", 09.07.2017. Disponible en: http://www2.latercera.com/noticia/corte-suprema-acuerdarebajar-la-condena-al-agresor-nabila-rifo/ [Visitado el 17.06.2018].

LA TERCERA (2016b): "Coyhaique: Mujer es encontrada con fracturas y sin sus ojos en vía pública", 14.05.2016. Disponible en: http://www2.latercera.com/noticia/coyhaique-mujeres-encontrada-con-fracturas-y-sin-sus-ojos-en-via-publica/ [Visitado el 04.07.2018].

LAS ÚLTIMAS NOTICIAS (2017): "Eminencias del Derecho critican fallo de la Suprema en el caso de Nabila Rifo", 14.07.2017. Disponible en: http://www.lun.com/Pages/NewsDetail.aspx?dt=2017-07-14\&PaginaId=16\&bodyid=0 [Visitado el 17.06.2018].

MEGA (s/f): YouTube Channel. Disponible en: https://www.youtube.com/user/programasmega [Visitado el 11.06.2018].

MEGA (s/f): Mega Sitio Corporativo. Disponible en: http://www.mega.cl/home/ [Visitado el 29.06.2018].

MIRROR (2017): "Man jailed for pulling out girlfriend's EYES in middle of street after he told her she cooked food "badly",, 04.05.2017. Disponible en: https://www.mirror.co.uk/news/world-news/man-jailed-pulling-out-girlfriends-10352505 [Visitado el 11.07.2018].

PODER JUDICIAL (2017a): "Infografia Historia Judicial del Caso Nabila Rifo", Facebook, 13.07.2017, en: https://www.facebook.com/PoderJudicialdeChile/posts/[infografía]historia-judicial-del-caso/1378430318919729/ [Visitado el 11.08.2018].

PODER JUDICIAL (2017b): "Infografía Historia Judicial del Caso Nabila Rifo", Twitter, 13.07.2017, en: https://twitter.com/PJudicialChile/status/885650116648030208 [Visitado el 11.07.2018].

PODER JUDICIAL TV (2017b): "Alegatos de apertura juicio oral "caso Nabila Rifo" (1)", 14.03.2017. Disponible en: http://www.poderjudicialtv.cl/sin-categoria/alegatos-deapertura-juicio-oral-caso-nabila-rifo-1/ [Visitado el 04.07.2018].

PODER JUDICIAL TV (2017c): "Caso Nabila Rifo: Juicio oral de Mauricio Ortega, acusado por femicidio frustrado (1) 23 marzo 2017”, 28.03.2017. Disponible en: http://www.poderjudicialtv.cl/esta-semana/caso-nabila-rifo-juicio-oral-de-mauricioortega-acusado-por-femicidio-frustrado-1-23-marzo-2017/ [Visitado el 11 .08. 2018].

PODER JUDICIAL TV (2017d): "Caso Nabila Rifo: Ministro Lamberto Cisternas realiza punto de prensa", Youtube Online Video, 11.07.2017. Disponible en: https://www.youtube.com/watch?v=J9PaPG3j-Bw [Visitado el 11.08.2018].

PODER JUDICIAL TV (2017e): "Noticiero Judicial: Caso Nabila Rifo: Conozca los fundamentos de la Corte Suprema", Youtube Online Video, 20.07.2017. Disponible en: https://www.youtube.com/watch?v=9XOMYsfo0Po [Visitado el 11.08.2018].

PODER JUDICIAL TV (s/f): Poder Judicial TV Sitio Corporativo. Disponible en: http://www.poderjudicialtv.cl/ [Visitado el 11.06.2018].

SOYCHILE (2016): "Desconocido atacó a mujer, le sacó los ojos y la dejó con múltiples fracturas en Coyhaique", 14.05.2016. Disponible en: http://www.soychile.cl/Santiago/Policial/2016/05/14/393276/Desconocido-ataco-amujer-le-saco-los-ojos-y-la-dejo-con-multiples-fracturas-en-Coyhaique.aspx [Visitado el 13.06.2018].

SOYCHILE (s/f): Sitio Corporativo. Dsiponible en: http://www.soychile.cl/ [Visitado el 11.06.2018]. 
TELE 13 (2016a): "Impacto por ataque a mujer en Coyhaique", 15.05.2016. Disponible en: http://www.t13.cl/videos/nacional/video-impacto-ataque-mujer-coyhaique [Visitado el 13.06.2018].

TELE 13 (2016b): "Bachelet visitó a Nabila Rifo en la ex Posta Central de Santiago", 18.05.2016. Disponible en: http://www.t13.cl/noticia/nacional/mujer-agredida-coyhaique-bacheletvisito-nabila-rifo-ex-posta-central-santiago [Visitado el 16.06.2018].

TELE 13 (2017): "8 detenidos tras protestas por condena de agresor de Nabila Rifo", 11.07.2017. Disponible en: http://www.t13.cl/videos/nacional/video-8-detenidos-protestas-condenaagresor-nabila-rifo [Visitado el 17.06.2018].

TELE 13 (s/f): Tele 13 Sitio Corporativo. Disponible en: http://www.t13.cl/ [Visitado el 12.06.2018].

TELEVISION NACIONAL DE CHILE (s/f): 24 horas Sitio Corporativo. Disponible en: http://www.24horas.cl/ [Visitado el 11.06.2018].

TELEVISION NACIONAL DE CHILE (s/f): Televisión Nacional de Chile Sitio Corporativo. Disponible en: http://www.tvn.cl/ [Visitado el 29.06.2018].

TELEVISIÓN NACIONAL DE CHILE (2017): "Rosita Alvarado sobre Nabila Rifo "yo creo que ella se lo busco", 06.04.2017. Disponible en: http://www.tvn.cl/programas/muybuenosdias/destacados/rosita-alvarado-sobre-nabilarifo-yo-creo-que-ella-se-lo-busco-2348575 [Visitado el 12.06.2018].

TELEVISIÓN NACIONAL DE CHILE (2017b): "Los polémicos dichos de Rosita Alvarado hacia Nabila Rifo | Muy buenos días” YouTube Online Video, 06.04.2017. Disponible en: https://www.youtube.com/watch?v=0jTeSBvPWu0 [Visitado el 17.06.2018].

TELEVISIÓN NACIONAL DE CHILE (2017c): "Muy buenos días ¡Frente a frente! Comparamos las declaraciones de Nabila y Ortega" YouTube Online Video, 24.03.2017. Disponible en: https://www.youtube.com/watch?v=3i7wnmXsfyk [Visitado el 17.06.2018].

WARNER MEDIA GROUP (s/f): "Turner Broadcasting System, Inc. to Acquire Chilevisión”, 25.08.2010 Disponible en: https://www.warnermediagroup.com/newsroom/pressreleases/2010/08/25/turner-broadcasting-system-inc-to-acquire-chilevisi-n [Visitado el 12.07.2018]. 